\title{
Research Square \\ Solar Driven Agricultural Greenhouse Integrated with Desalination System; Energy-Water-Food Nexus
}

Kabir Abdullahi ( $\sim$ kabir.abdullahi@ejust.edu.eg)

Egypt-Japan University of Science and Technology https://orcid.org/0000-0003-2315-1568

Alaa Salah

City of Scientific Research and Technological Applications

Hassan Fath

Egypt-Japan University of Science and Technology

\section{Research Article}

Keywords: Sustainable greenhouse, Desalination, Condenser, Solar distillers, Natural ventilation

Posted Date: May 22nd, 2020

DOI: https://doi.org/10.21203/rs.3.rs-23546/v1

License: (1) This work is licensed under a Creative Commons Attribution 4.0 International License.

Read Full License 
$4 \quad{ }^{1}$ Department of Environmental Engineering, Egypt-Japan University of Science and

$6 \quad{ }^{2}$ Abuja Environmental Protection Board, Cadastral Zone 776, Central Business

$8 \quad{ }^{3}$ Computer Based Engineering Applications Department, Informatics Research

9 Institute, City of Scientific Research and Technological Application, New Borg E1 


\section{Abstract}

14 This study presents the effective performance of a sustainable solar driven agricultural

15 greenhouse $(\mathrm{GH})$ self-reliant of energy and irrigation water via desalination. The $\mathrm{GH}$ is

16 furnished with infrastructures such as; (i) - an inlet condenser for cool air exchanger

17 and partial water production, (ii) - an internal cavity for crop production (iii) - roof

18 transparent solar distillers (TSD) for solar desalination and partial shading and (iv)- a

19 thermal chimney for natural air ventilation. A mathematical model is developed to

20 predict the performance of the sustainable GH system. A coupled approach of

21 MATLAB/Simulink and computational fluid dynamics (CFD) based on three

22 simulation models were used: solar radiation, thermal energy balance and CFD model.

23 Two parametric studies were carried out. The first one analyzed the effects of different

24 air velocity on the system thermal performance and natural ventilation rate. The second

25 study assessed the effects of different covering material on the transmitted solar

26 radiation. Results from the model shows that $8.5 \mathrm{MJ} / \mathrm{m}^{2}$.day of total solar radiation is

27 transmitted into the GH. The greenhouse air temperature is lowered by $5^{\circ} \mathrm{C}$ and

28 humidified by $20 \%$, to satisfy the required conditions necessary for plant growth.

29 Maximum water yield of $11.5 \mathrm{~L} / \mathrm{m}^{2}$.day was obtained, aided by the addition of Al-metal 

net. Additionally, $2.6 \mathrm{kWh} / \mathrm{m}^{2}$.day of power is consumed by the air-cooling condenser.

31 At air velocity of $0.3 \mathrm{~m} / \mathrm{s}$, there is a natural tendency of air to flow by draft, due to air

32 temperature difference of up to $4{ }^{\circ} \mathrm{C}$. Furthermore, glass and EVA cover materials

33 transmit 52 and $48 \%$ of solar radiation into the GH respectively. The proposed system

34 will enable the parallel production of water and food and enhance economical plant 35 productivity.

36 Keywords: Sustainable greenhouse; Desalination; Condenser; Solar distillers; Natural 37 ventilation 


\section{Introduction}

Solar driven agricultural greenhouse integrated with desalination system represent one of the best applied example of the energy-water-food nexus. This integrated system

41 not only provide its own irrigation water, it also provide a controlled environment necessary for food production and has the potential to generate electrical energy via

43 photovoltaic (PV) cells [1]. The UN world water development report 2015 states that

44 by 2050 , an increase in $55 \%$ of global water demand will be observed, and the world's

45 agricultural sector will be required to generate $60 \%$ more food, reaching up to $100 \%$

46 in the developing nations [2]. The 2017 World Health Organization (WHO) reports that,

47 with the prevailing climate change situation, more than $50 \%$ of the world population

48 will exist in high water stress areas by 2030 [3]. The intensifying water crisis is also

49 associated to food production since agriculture accounts for $70 \%$ of all freshwater

50 usages [4], hence fresh water supply is one of the most significant future issues [5]. The

51 evident increasing demand for food, energy and water, coupled with the ever-increasing

52 scarcity of land resources, this study aims to tackle these issues by proposing the

53 investment of solar energy into desalination and greenhouse systems.

54 An agricultural greenhouse $(\mathrm{GH})$ is an enclosed transparent house used to protect 
55 crops from critical ambient climate conditions and pests, and provide the opportunity

56 to adjust the indoor microclimate suitable for crop growth and production, both in terms

57 of quantity and quality [6]. GH enables year-round crop production and improves the

58 yield and quality of crops through control of the physical environmental factors such as

59 light, water, temperature, relative humidity, $\mathrm{CO} 2$ concentration, and ventilation [7]. GH

60 technology can guarantee the sustainable and secure food production by increasing the

61 production yield up to ten times more [1], and decreasing the $11.8 \mathrm{~m}^{3} / \mathrm{d}$ per capita water

62 requirements by $80 \%$ compared to conventional cultivation [2, 3]. However, GH

63 energy consumption can be up to one hundred times more [8]. Thus, one of the

64 substantial technical challenges of GHs is management of energy consumption [9].

65 Renewable energy technologies provide access to the secure and environmentally

66 sustainable supply of energy and can be cost-effective as well [10]. For sustainability,

67 solar thermal appears to be the most sustainable energy resource [11]. Since the GH

68 itself functions as a solar collector, solar energy utilization can lead to a reduction in

69 production cost [12].

70 All GH systems, irrespective of physiographical location, consist of essential

71 climate control mechanisms and components, and depending on their design and 
complexity, they are capable of providing a major or minor amount of environmental

73 control, and consequent plant growth and productivity. The major fundamental GH

74 microclimate environment is strongly reliant on available solar radiation, temperature

75 manipulation, humidity control, $\mathrm{CO}_{2}$ concentration and air ventilation [13, 14].

76 Temperature management is essential to influencing plant growth and development,

77 with an average range of $17^{\circ} \mathrm{C}$ to $27^{\circ} \mathrm{C}$, over which there is a near linear positive

78 response in terms of increased growth [15]. Humidity (RH) in GHs is controlled to

79 ensure adequate transpiration and also reduces fungal infection. As a general guide, it

80 is often recommended that $\mathrm{GH}$ RH be maintained within the range $60-90 \%$ suitable for

81 healthy plant growth. $\mathrm{CO}_{2}$ enrichment is also vital in $\mathrm{GH}$ production with most plants

82 showing a positive response to increased $\mathrm{CO}_{2}$ levels up to $1,000-1,500$ ppm $[13,15]$.

83 Ventilation is necessary during summer periods to prevent excess rise of GH

84 temperature above the ambient air. The rate of ventilation varies between 20 and 180

85 air changes per hour [3].

86 Agricultural GHs have shown great complexity and diversity depending on its

87 location across the globe. For cold climates, GH are specifically designed to provide a

88 warmer environment for crops to grow, such as the so-called active (or heated) 
89 greenhouses equipped with several heating devices. Meanwhile, GH combined with

90 shading, ventilation (passive GH), or cooling systems are used in hot climates to control

91 the inner environment. Ghani et al. [16] comprehensively reviewed several GH designs

92 features in hot and arid climates. The review involved GH shape, dimensions,

93 orientation, cooling methods, and the renewable technologies applicable in GHs. Due

94 to the continuous increase in energy prices and climate concerns, the energy

95 consumption in GH systems became one of the main challenges especially in hot

96 climate [17]. In general, two methods can be used to reduce the energy consumption of

97 agricultural GH systems. These methods are the integration of semi-transparent

98 photovoltaic (PV) and solar distillation units on the GH roof $[18,19]$. Several integrated

99 GH systems utilizing solar radiation above plant needs have been documented. Yano et

100 al. [20] established two prototypes of semi-transparent- photovoltaic (PV) modules

101 proposed for GH roof applications. The yearly electrical energy production estimate

102 showed that these PV modules are potentially suitable for GHs in high solar radiation

103 regions, where electrical energy production could be high. Yohannes and Fath, [21]

104 developed an agriculture GH model with in-built Transparent Photo-Voltaic (TPV)

105 panels to be energy self-sufficient and produce irrigating water for the hot 
107 of cooling system condenser properties on the interior climatic conditions inside a GH

108 integrated with on-roof TPV. The results demonstrate that the GH satisfy the required

109 micro-climatic conditions for plants growth and be self-sufficient of irrigating water

110 during a hot day for Abu Dhabi, UAE.

111 Many studies are concerned with the integration of a solar distillers with a GH

112 system. Fath and Abdelrahman [22] studied the numerical performance of a GH

113 covered with on-roof transparent solar still at $30^{\circ}$ inclination. The $\mathrm{GH}$ shows to

114 withstand harsher environmental conditions when integrated with an on-roof solar still.

115 Radhwan [23] developed a stepped-solar-still for GH heating and humidification. The

116 total daily yield of the solar stills is about $4.92 \mathrm{~L} / \mathrm{m}^{2}$, and the daily average efficiency

117 is about $63 \%$. Chaibi [24] performed a numerical and experimental deviation study of

118 a small water desalination module to be placed on a GH roof, and obtained a $25 \%$

119 deviation between calculated and measured water production. Mari et al. [25] conduct

120 an experimental and theoretical study to examine the performance of 28 on-roof solar

121 still integrated into a GH. Results revealed approximately 52\% reduction in solar

122 radiation inside the $\mathrm{GH}$, the theoretical model also overestimate the water yield by 
123 approximately $15 \%$ higher than the measured one. Radhwan and Fath [26]

124 experimentally investigate the thermal performance of an agricultural GH consisting of

12524 on-roof solar stills distillation system. For the summer condition of Jedda, Saudi

126 Arabia, the results showed that the temperatures inside the GH are $8-10^{\circ}$ (at GH inlet)

127 and $3-6^{\circ}$ (at GH outlet) below ambient temperature. The relative humidity inside the

$128 \mathrm{GH}$ is found to vary between $20 \%$ and $35 \%$ above ambient conditions, satisfying the

129 comfort zone of the plant growth. They obtained a relatively small water production

130 range from 1.7 to $2.5 \mathrm{~L} / \mathrm{d}$, mainly due to relatively high glass temperature. A solar $\mathrm{GH}$

131 with built-in water desalination system and humidification-dehumidification (HDH)

132 system was analytically studied [27]. This integrated system uses the excess solar

133 radiation (excess of the crop requirement) to desalinate water and reduce the cooling

134 load of the greenhouse. The results showed that, by controlling the fresh-air ratio and

135 condenser by-pass ratio, the interior climate of the GH will satisfy the comfort zone for

136 plant growth. The system can produce about $8.6 \mathrm{~kg} / \mathrm{m}^{2}$.day of water. Rabhy et al. [28]

137 developed an experimental and numerical analyses of a transparent solar distiller

138 suitable for agricultural GH. The system results show about $37.5 \%$ of irrigation water

139 can be produced, whiles the power consumption of the GH cooling system can be 
140 reduced by $60 \%$. Other developed integrated system include the 'Watergy' GH system,

141 developed for integrated water treatment, solar thermal energy collection and advanced

142 food production suitable in the arid and Mediterranean regions [29]. De Zwart [30] also

143 developed a system called 'Sunergy', which is a semi-closed GH that is closed during

144 periods with high solar radiation, to enable harvesting of solar energy at moderately

145 high temperatures, and allows ambient air exchange during cloudy days and at night,

146 for dehumidification. Seawater GH is another strategy developed based on solar

147 distillation units for arid countries in the Middle East to challenge the high temperature,

148 water salinity, and water scarcity problems. These concepts were examined using both

149 experimental setups [31] and energy and mass balance models [32]. The main

150 conclusions of this studies were that semi-transparent solar still modules can be

151 integrated into a GH roof in order to control the solar radiation and produce fresh water,

152 which could meet the irrigation demand of GHs.

153 The main contribution of this study is to integrate all the elements of energy-water-

154 food nexus into a system capable of producing food, water and reducing energy

155 consumption, while also cutting costs and improving the quality of the combined

156 services. A sustainable GH system is developed, which was integrated with transparent 
157 solar distillers (TSD) and equipped with a chilled water condenser at the entry of the

158 GH cavity. The design concepts are based on micro-climate control strategies,

159 renewable energy water production sources and application of innovative covering

160 materials. Firstly, it presents and uses a method to couple MATLAB/Simulink with

161 computational fluid dynamics (CFD) for GH climate modelling. The MATLAB model

162 were used to predict surface temperatures, condenser effects, water production and

163 power consumption, which were then used as boundary condition in the CFD model to

164 determine the micro-climatic condition of the GH cavity. Secondly, the effects of

165 different operating parameters on the micro-climatic conditions inside the GH (air

166 temperature and relative humidity), water production and electrical power consumption

167 of the GH are investigated. The simulations are carried out to evaluate the performance

168 of the GH for the metrological conditions of a Mediterranean climate. Furthermore, the

169 GH model was analyzed for its natural ventilation performance. This developed model

170 will provide the basis for further investigation and designing next generation GHs, for

171 sustainable agriculture in the MENA-GCC and other water-stressed regions.

172 2. Materials and methods

173

2.1 System Description 

system consist of an interior glass covered plant cavity, a chilled water condenser at the entry of the GH cavity, a vertical and inclined riser, set of transparent solar distillers

177 placed on the risers, a thermal chimney and a vertical down comer channel. The GH 178 structure was designed facing the south in order to receive maximum solar radiation 179 whiles minimizing heat loss. Geometrical dimension of the GH is giving in Table 1.

180 Ventilation fresh air (a1) at ambient condition enters the GH through an inlet 181 condenser. In the condenser, the air is partially cooled and humidified, depending on 182 the ambient temperature and relative humidity. The cool air (a2) then mixes with the 183 bypassing air and moves through the interior GH cavity (ai), where it gains heat and 184 water vapor through convection and plant transpiration. The heated air then leaves the 185 GH cavity through an outlet condenser (a3), where it gets cooled to saturation condition 186 and condense the water derived from plants transpiration. The cool air (a4) then mixes 187 with the bypassing air and flow through the vertical (a5) and inclined risers (a6), to gain 188 extra heat from solar stills and glass covers. Depending on the seasonal condition, the 189 heated air then either leaves the GH to the atmosphere through a thermal chimney or 190 partially recirculated from the down comer (a7) into the GH cavity to mix with the fresh 
191 ambient air. In the current paper, the outlet condenser is not active (switched off) and

192 no air recirculation through the down comer.

193 The integrated transparent solar distiller is illustrated in Fig. 2. The solar distillers

194 are oriented to face the south with a cover tilt angle of $30^{\circ}$, which is equal to the solar

195 latitude angle of the target study area [28]. The solar distillers are designed to be

196 transparent to enable solar light reach plant region for photosynthetic process. Further,

197 the solar distillers will serve as partial shading thereby reducing the GH cooling load

198 and utilize the excess solar radiation (above plant need) for water desalination. The

199 solar still desalination works based on evaporation and condensation [2]. Solar radiation

200 passes through the glass cover and converts the saline water into vapor. The water vapor

201 flows up and condenses on the inner surface of the inclined cover due to temperature

202 differences. The purely desalinated water is then collected via the distillation trough

203 [33]. Due to the low gained output ratio (GOR) of solar still desalinations, an aluminum

204 (Al) metal net is added to the base of the distillers to enhance productivity by increasing

205 the absorption of solar radiation. A parametric study is performed to determine the

206 effect of net area ratio on the total solar radiation transmitted into the GH cavity. 
209 ANSYS-CFD models are used in three steps of calculations. The process is summarized

210 as follows; Firstly, a transient mathematical model was used to calculate the

211 instantaneously incident global solar radiation received by the GH covers based on a

212 Clear Day Solar Flux Model [27, 34]. Secondly, a transient thermal model based on

213 energy and mass balance equations were used for each component of the GH system to

214 predict the thermal behavior of the system. The equations were solved using MATLAB.

215 Finally, a 2-D ANSYS-CFD model was then developed to determine the microclimatic

216 condition (in terms of air velocity, temperature, relative humidity and water vapor)

217 within the GH cavity.

Fig. 3 shows briefly the system methodology. The calculated solar radiation by the

219 clear sky model and the ambient conditions (of temperature, RH, wind speed) were

220 used as inputs for the thermal model. The glass surface temperatures and condenser air

221 temperature predicted by the thermal model were used as input for the boundary

222 condition of the CFD model. The continuity, energy, species and mass transport

223 equations were solved numerically. The CFD model methodology will be explained in

224 Section 2.2.3. 
232

233

234 is the diffused radiation. $I_{R \beta}$ is the reflected solar radiation.

\subsubsection{Solar Radiation Model} surface is predicted according to Eqns. 1-6 [27, 34].

$$
I_{\beta}=I_{B \beta}+I_{D \beta}+I_{R \beta}
$$

$$
I_{D \beta}=C * A e^{-k * \sec \theta_{z}} * 0.5(1-\cos \beta)
$$

GH depends on the declination \& solar altitude angle, latitude and surface inclination angle. In this model, the instantaneous global solar radiation incident on each GH

Where $I_{\beta}$ is the incident global solar radiation, $I_{B \beta}$ is the direct beam radiation. $I_{D \beta}$

$$
\cos \theta_{z}=\sin \delta \sin \varnothing+\cos \delta \cos \emptyset \cos \omega
$$

Declination angle $(\boldsymbol{\delta})$ is calculated as below,

238

$$
\delta=23.45 \sin \left(360 \frac{284+n}{365}\right)
$$

239 To calculate the total solar radiation received on the GH and TSS components, the Eqn.

240 below is used, 


$$
s_{t}=\sum A_{i} I_{i}
$$

242 Where $\boldsymbol{A}_{\boldsymbol{i}}$ and $\boldsymbol{I}_{\boldsymbol{i}}$ represent the area and the total incident radiation reaching the $\mathrm{i}^{\text {th }}$

243 section. The values of $A, k$ and $C$ are $1069 \mathrm{~W} / \mathrm{m}^{2}, 0.205$ and 0.134 respectively for

$24421^{\text {st }}$ June giving from the ASHRAE model [35]. Solar radiation inside the GH is

245 calculated based on the above equations using the transmissivity of each cover material

246 layer and water.

\subsubsection{Thermal Model}

248 To predict the transient surface temperature of the GH cover components, heat air

249 exchange, condensed water from moist air condenser, yield produced from the TSS and

250 the electrical power consumed by the condenser are achieved from the equations of

251 energy and mass balance. The mathematical model is developed with the following

252 assumptions [36]:

253 (1) Clear sky solar radiation model is applied

254 (2) Air is assumed transparent for long and short-wave radiation and its absorptivity is

255 neglected

256 (3) Plant thermal properties are equivalent to that of water due to the high content of

257 water in the plant 
258 (4) Relative humidity and temperature of circulating air are presumed to be uniform

259 (5) GH component temperatures are lumped (i.e. same throughout)

260 (6) Temperature of earth below the ground is assumed constant at $15{ }^{\circ} \mathrm{C}$ and evaporation

261 of the floor is negligible.

262 (7) GH is assumed to be properly insulated with no leakage through the walls.

263 (8) Thermal analysis is based on quasi-steady state conditions inside the greenhouse

264 due to transient behavior for short time intervals and heat transfer is one-dimensional.

265 The main governing equations are listed below, Eqns. 7-11, [19, 27]

266 For transient temperature change for each GH and TSD components;

267

$$
\frac{d T}{d t}=\frac{1}{M \cdot C_{p}}\left(\sum Q_{\text {in }}-\sum Q_{o u t}\right)
$$

268 For air flow, Eqn 8 applies;

$$
m_{a}\left(h_{o}-h_{i n}\right)=\left(\sum Q_{i n}-\sum Q_{o u t}\right)
$$

270 For condensed water from the condenser;

$$
m_{c}=m_{c o n d}\left(w_{\text {in }}-w_{\text {out }}\right)
$$

272 From the TSD, the produced distillate is calculated as follows;

273

$$
m_{T S D}=\frac{Q_{e}}{h_{f g}}
$$

274 The electrical power is calculated as follows; 


$$
\text { power }=\frac{m_{\text {cond }}\left(h_{\text {in }}-h_{\text {out }}\right)}{C O P}
$$

276 The input data for the thermal model are the calculated solar radiation and the climate

277 metrological data of temperature, relative humidity and wind speed. Fig. S1

278 (supplementary material) illustrates the universal energy and water vapor fluxes within

279 the GH, which were used to define the mass balance and energy balance equations of

280 the proposed model. Fig. S2 (supplementary material) illustrates the flow chart of the

281 mathematical model procedure.

$282 \quad 2.2 .3 \quad$ CFD Model

283 2.2.3.1 Governing Equations

284 To study the internal climatic condition of the GH cavity, heat transfer processes

285 are solved using the CFD code (ANSYS Fluent). The flow inside the GH was

286 considered as two-dimensional, an-isothermal, fully turbulent and incompressible flow.

287 The CFD code uses the finite volume method for solving the governing equation of

288 fluid flow and heat transfer based on mass, energy and momentum conservation, i.e.

289 the Navier-Stokes equation. The transport equation of air flow based on the Navier-

290 Stokes equation is given by [37];

$$
\frac{\partial \rho \psi}{\partial t}+\nabla \cdot(\rho \vec{v} \psi)=\nabla\left(\ulcorner\nabla \psi)+S_{m}\right.
$$


292 Where $\rho, t, \psi$ and $\nabla$ are the density, time, concentration variable and divergence 293 operator respectively. $\vec{v}$ and $\Gamma$ are the velocity vector and diffusion coefficient. The 294 source term, $S_{m}$ is added due to crop transpiration. species sensible enthalphy respectively.

$$
\frac{\partial}{\partial x_{i}}\left[u_{i}(\rho e+p)\right]=\frac{\partial}{\partial x_{i}}\left[\left(K+\frac{C_{p} \mu_{t}}{P r_{t}}\right) \frac{\partial T}{\partial x_{i}}-\sum_{j} h_{j} J_{j}\right]+S_{h}
$$

300 fraction was activated using the mass fraction of $\mathrm{H} 2 \mathrm{O}(\mathrm{w} / \mathrm{w})$ described by equation 14 $301 \quad[38]$.

$$
\frac{\partial}{\partial t}\left(\rho Y_{H_{2} O} \vec{v}\right)=\frac{\partial}{\partial t}\left[\left(\rho D_{H_{2} O}+\frac{\mu_{t}}{S c_{t}}\right) \frac{\partial Y_{H_{2} O}}{\partial t}\right]+S_{H_{2} O}
$$

303 Where $S_{\mathrm{H}_{2} \mathrm{O}}$ represent water vapor added or removed from the air due to condensation or evaporation. The constant $D_{\mathrm{H}_{2} \mathrm{O}}$ is the diffusion coefficient of water vapor into air 305 which is equal to $2.88 \times 10^{-5} ; S c_{t}$ is the turbulent Schmidt number which is equal to 306 0.7 .

307 To account for turbulences, the standard $\mathrm{k}-\varepsilon$ model with wall function was used [39]. 308 This model solves for turbulent kinetic $(\mathrm{k})$ and the rate of dissipation of energy $(\varepsilon)$ in 
311 giving below, respectively.

312

$$
\begin{gathered}
\frac{\partial}{\partial t}(\rho k)+\frac{\partial}{\partial x_{i}}\left(\rho k u_{i}\right)=\frac{\partial}{\partial x_{j}}\left[\left(\mu+\frac{\mu_{t}}{\sigma_{k}}\right) \frac{\partial k}{\partial x_{j}}\right]+G_{k}+G_{b}-\rho \varepsilon-Y_{M}+S_{k} \\
\frac{\partial}{\partial t}(\rho \varepsilon)+\frac{\partial}{\partial x_{i}}\left(\rho \varepsilon u_{i}\right)=\frac{\partial}{\partial x_{j}}\left[\left(\mu+\frac{\mu_{t}}{\sigma_{\varepsilon}}\right) \frac{\partial \varepsilon}{\partial x_{j}}\right]+C_{1 \varepsilon} \frac{\varepsilon}{k}\left(G_{k}+C_{3 \varepsilon} G_{b}\right)-C_{2 \varepsilon} \rho \frac{\varepsilon^{2}}{k}+S_{\varepsilon}
\end{gathered}
$$

314 From the equations, $G_{k}$ and $G_{b}$ represent the generated turbulence kinetic energy due

315 to mean velocity gradients and buoyancy respectively, $Y_{M}$ represents the dilation

316 fluctuation contribution in compressible turbulences. The constants are giving below

$317 \quad[22]$

$$
C_{1 \varepsilon}=1.44, C_{2 \varepsilon}=1.92, C_{\mu}=0.09, \sigma_{k}=1.0, \sigma_{\varepsilon}=1.3
$$

The plant was considered as porous media with the source term governed by the Darcy-Forchheimer equation which include the viscous loss term and inertial resistance loss term [41].

The Darcy law is giving by;

$$
S_{i}=-\left(\frac{\mu}{\alpha} u+C_{2} \frac{1}{2} \rho|u| u\right)
$$

324 Where $\alpha$ and $C_{2}$ represent the permeability and inertial resistance factors of the

325 porous medium, whose values are chosen to represent the crop under consideration. 
328 The geometrical characteristics of the GH were assigned according to what is presented

329 in Table 1. A 2D structured mesh was generated using Ansys Mesh workbench, which

330 consist of approximately 71,000 cells. A structured Cartesian mesh was chosen to limit

331 the numerical diffusion of errors and facilitate calculation convergence.

332 Four different element sizes of the structural grids are used to test the grid

333 independence; including the coarse $(0.5 \mathrm{~m})$, medium $(0.3 \mathrm{~m})$, fine $(0.1 \mathrm{~m})$ and very fine

$334(0.05 \mathrm{~m})$. Two of the simulation parameters, air velocity out $\left(\mathrm{V}_{\text {out }}\right)$ and pressure in $\left(\mathrm{P}_{\text {in }}\right)$,

335 are selected to evaluate the effect of the grid density. The $\mathrm{V}_{\text {out }}$ and $\mathrm{P}_{\text {in }}$ calculated from

336 the coarse and medium grid deviate significantly, while the fine and very fine grid

337 represent similar results. Therefore, the fine grid system was used to conduct our

338 simulations, considering the efficiency and computing accuracy. The quality of the grid

339 was checked by applying the skewness parameter. The skewness parameter indicates

340 how ideal a cell shape is. The mesh used gave a maximum skewness parameter of 0.5 ,

341 which falls into the "good" range, according to the Ansys Fluent manual [42].

343 Academic ANSYS FLUENT V18.2 was used to carry out the CFD analysis. The 
344 computational domain was meshed using a two-dimensional structured mesh with

34571,748 cells. The CFD code solves the transport equation using the finite volume

346 method for each cell. To account for pressure velocity coupling, the SIMPLE algorithm

347 was used [41]. The CFD numerical model parameters are enumerated in Table 2. The

348 convergence criterion is set to $10^{-6}$ for the continuity, momentum and turbulence

349 equations, and $10^{-8}$ for the energy equation.

350 The glass cover and air temperature variations, which were predicted by the thermal

351 model, were considered as the boundary conditions for the CFD model. The interior

352 GH cavity were simulated in the CFD model for full day, in an hourly quasi-steady-

353 state condition. The main working fluid in this simulation is a mixed species of water

354 vapor and air, whose density depends on the operating pressure while the specific heat,

355 thermal conductivity and viscosity were taken as a function of temperature. The plant

356 region is simulated as porous material with viscous resistance $\boldsymbol{\alpha}^{\mathbf{- 1}}=2.532 \mathrm{~m}^{-2}$, inertial

357 resistance $C_{2}=1.6 \mathrm{~m}^{-1}$ and porosity of $40 \%$. The participating solid material in the

358 porous media calculation is considered as a fully developed tomato plant whose

359 properties are detailed in Table 3. Thermo-physical properties of other materials like

360 glass, water and ground are giving in Table $4[43,44]$. 
The general performance of the GH system on four different air velocities $(0.6,0.5$,

363

$0.4,0.3 \mathrm{~m} / \mathrm{s}$ ) were examined. Four different cover materials were also studied; (a) glass,

364 (b) Ethylene vinyl acetate film (EVA), (c) polyethylene (P.E), (d) polyvinyl chloride

365 film (PVC), whose optical properties are given in Table 5 [43, 45].

\section{3. Results and discussion}

\subsection{Model Validation}

To validate this model, the interior GH temperature and relative humidity is firstly

compared between simulation and published data of [27] for the ambient condition of

$21^{\text {st }}$ June. Fig. 4 shows the simulation and validation data of the average air temperature and relative humidity inside the GH cavity. The trend of the air temperature (Fig. 4a)

shows close agreement especially during solar hours, the difference between the

373 simulation and validation values was always less than $1{ }^{\circ} \mathrm{C}$. Regarding the relative

374 humidity (Fig. 4b), the agreement was particularly good during the solar hours, the 
378 the two values suggest that the simulation of temperature and relative humidity

379 propagation inside the GH interior is successful. Therefore, in view of the validation

380 results of the model, the CFD model proved to be a satisfactory predictive model that

381 could be used to predict the temperature and airflow distributions in GHs. Hence, the

382 CFD can therefore, be a very useful tool in the study of the internal microclimatic

383 conditions of the GH system.

\subsection{Effect of TSD on transmitted solar radiation}

385

The key for designing transparent GHs is to get enough solar radiation into the GH.

386 The threshold of solar intensity required for plants photosynthetic process is 8.5

$387 \mathrm{MJ} / \mathrm{m}^{2}$.day $[46,47]$. During the summer, excess solar radiation about twice the plant

388 need is available. To utilize the excess solar intensity, this study integrates transparent

389 solar distillers into GH roof. To improve productivity of the distillers, an Al-metal net

390 were added to the base of the solar distillers to increase solar absorptivity and decreases

391 transmissivity into the GH. Fig. 5 shows the effect of the Al-metal net on the transmitted

392 solar radiation and the daily variation of the direct solar radiation reaching the GH.

393 Firstly, we study the effect of the Al-metal net area ratio to the solar still base. In Fig.

$3945 \mathrm{a}$, when the net area ratio is zero (i.e. no metal net added), $14 \mathrm{MJ} / \mathrm{m}^{2}$.day of total solar 
395 radiation is available during the day. By increasing the net-area ratio, the total solar 396 radiation transmitted into the $\mathrm{GH}$ decreases, reaching the required threshold of 8.5

$397 \mathrm{MJ} / \mathrm{m}^{2}$.day at a net area ratio of 0.75 . Fig. $5 \mathrm{~b}$ present hourly variation of the transmitted 398 solar radiation into the GH through each cover, for the maximum radiation day of $21^{\text {st }}$ 399 June, with glass cover material. The solar intensity varied in a sinusoidal way with total 400 available direct solar radiation of $8.5 \mathrm{MJ} / \mathrm{m}^{2}$.day, the maximum value of $250 \mathrm{~W} / \mathrm{m}^{2}$ 401 recorded during solar hours. The solar distillers reduce the transmitted solar radiation 402 by $\sim 50 \%$. These solar intensity data were then used to compute the temperature on 403 individual roof and wall of the GH using the standard ASHRAE model.

\subsection{GH system operational performance}

The operational performance of the $\mathrm{GH}$ in terms of air temperature, relative humidity, freshwater production and power consumption of the air-cooling condenser

407 are analyzed. The evolution of these factors throughout the day for the examined air 408 velocity are presented.

410 for the $21^{\text {st }}$ of June, for the four examined air velocity and the ambient temperature. In

411 all cases, the GH air temperature is lower than the ambient temperature because of the 
412 effect of condenser air-cooling, and the solar distillers serving as a partial shading.

413 While the ambient air temperature varies between $24^{\circ} \mathrm{C}$ to $31^{\circ} \mathrm{C}$, the $\mathrm{GH}$ (cavity)

414 average air temperature varied from $20^{\circ} \mathrm{C}$ to $26^{\circ} \mathrm{C}$. During this day, as the sun rose

415 around 6:00 AM, GH temperature began to rise until it reached $26^{\circ} \mathrm{C}$. As the sun set,

416 around 6:00 PM, the solar radiation intensity and ambient temperature dropped, the $\mathrm{GH}$

417 air temperature also dropped accordingly to a value below $22^{\circ} \mathrm{C}$. Despite the change in

418 air velocity, the GH air temperature were similar, satisfying the required condition

419 needed for plant growth.

In Fig. 7, the average air relative humidity inside the GH cavity and the ambient

421 for the four examined air velocities are giving. The $\mathrm{GH}$ air relative humidity is 15 to

$42220 \%$ higher than that of the ambient. This is because the air gets humidified in the

423 condenser and from plant transpiration. The ambient relative humidity varies between

$42445 \%$ and $80 \%$, in the GH it varies between $60 \%$ and $90 \%$. The relative humidity obeys

425 the sinusoidal trend with its minimum value at midday. Favorably, lower relative

426 humidity at mid-day aid the air-cooling condenser in reducing the high ambient air

427 temperature. The difference of the average air relative humidity among the examined

428 air velocities are not important, since the mechanism of vapor transfer remains the same. 
429 In all cases, the air relative humidity inside the GH cavity is within the satisfactory

430 values (comfort zone) for plants growth.

431 Fig. 8 present the hourly accumulated water production from the TSD and the 432 condenser for the examined air flow rates. The addition of Al-metal net enhances the 433 productivity of the TSD, producing averagely over $60 \%$ of the accumulated water. The 434 major difference in water production from the examined air velocities is found in the 435 condenser distillate, since the condensed water production depends on the mass flow 436 rate of air passing through the condenser. At air flow rate of $0.3 \mathrm{~m} / \mathrm{s}$, over $9 \mathrm{~L} / \mathrm{m}^{2}$.day 437 of water is produced. The distillate water production increases with an increase in air 438 flow velocity, an additional $2.5 \mathrm{~L} / \mathrm{m}^{2}$.day of water production was observed at 439 increasing air flow velocity from 0.3 to $0.6 \mathrm{~m} / \mathrm{s}$. Overall, the $\mathrm{GH}$ system is capable of 440 producing freshwater which exceed the average irrigation water demand of a $\mathrm{GH}$ (2 $441 \mathrm{~L} / \mathrm{m}^{2}$.day) [28, 48], Fig. 9 shows the accumulated power consumed by the air-cooling condenser for the

443 examined air flow rates. At air flow rate of $0.3 \mathrm{~m} / \mathrm{s}, 1.3 \mathrm{kWh} / \mathrm{m}^{2}$.day of energy is 444 consumed by the air-cooling condenser to produce $2.7 \mathrm{~L} / \mathrm{m}^{2}$.day of fresh water. 445 Increasing the air flow rate from $0.3 \mathrm{~m} / \mathrm{s}$ increases the energy consumption by 0.43 
$446 \mathrm{kWh} / \mathrm{m}^{2}$.day for each step increase. This is due to the increase in mass flow rate of air

447 passing through the condenser. At $0.6 \mathrm{~m} / \mathrm{s}$, the energy consumption is about 2.6

$448 \mathrm{kWh} / \mathrm{m}^{2}$.day, producing $5.4 \mathrm{~L} / \mathrm{m}^{2}$.day of fresh water. Integrating an agricultural $\mathrm{GH}$

449 with transparent solar distillers decreases power consumption for air cooling by

450 approximately $60 \%$ [28]. For all examined air flow rates, the condenser consumed

451 reasonable amount of energy for air cooling and distillate production, these results are

452 consistent with Hassan et al. [19]

453 3.4 Optimal growing conditions

454 An appropriate microclimate for plant growth and development is characterized by

455 the solar light availability, when it is up to $8.5 \mathrm{MJ} / \mathrm{m}^{2}$.day, the temperature range

456 varying between 14 and $28^{\circ} \mathrm{C}$, RH of $60-90 \%$ and air velocity between 0.2 to $0.5 \mathrm{~m} / \mathrm{s}$.

457 In order to assess the efficiency of each examined air flow rate, distributions and

458 profiles for air velocity, temperature and humidity for the mid-day at a flow rate of 0.5

$459 \mathrm{~m} / \mathrm{s}$ are presented. Fig. 10 shows the CFD simulation results for $\mathrm{GH}$ air temperature,

460 velocity vectors and relative humidity contours at $12 \mathrm{P} . \mathrm{M}$ of $21^{\text {st }} \mathrm{June}$ with glass cover

461 material. At this time, the ambient air temperature is $304 \mathrm{~K}$, the outside relative

462 humidity is $46 \%$ and the wind speed is $0.5 \mathrm{~m} / \mathrm{s}$. 

temperature in the plant region is slightly cooler than the ambient air, with an average GH air temperature of $299 \mathrm{~K}$. This is due to the cooling effect created by the inlet condenser. The CFD model also shows the solar distiller region (roof) of the GH as the hottest surface, which intercept majority of the solar radiation. The GH air temperature is uniform for most of the GH cross section, with the left region of the cross section slightly warmer. This is due to the air heating by convection and plant transpiration as

470 it passes through the GH cavity, and transferring the heat to the GH roof, which

471 becomes warmer than other regions in the $\mathrm{GH}$.

Fig. 10(b) and (c) show the relative humidity and water mass fraction contours predicted by the CFD model at 12 P.M for the same set of boundary conditions. Fig.

474 10b shows an increase in humidity immediately after the condenser, since the air gets

475 humidified in the condenser unit. As the air flows in the plant region, the air becomes warmer and humidified from plant transpiration. The average air relative humidity in

477 the plant region is $62 \%$, which is higher than the ambient $\mathrm{RH}$ of $45 \%$. The water mass 478 fraction (Fig. 10c) also increases in a stream wise direction in the plant zone, due to 479 water vapor generated inside the plant region. The water mass fraction was slightly 
higher in areas with higher air temperatures (Fig. 10a), since hot air holds more water

481 vapor.

483 the 21 st June. The air velocity depends on the opening area, which is $1 \mathrm{~m}^{2}$, with an

484 average air velocity of $0.5 \mathrm{~m} / \mathrm{s}$ at the inlet opening. In the plant region, the air velocity

485 is damped due to high resistance of plant to air flow. This causes a strong stream of air

486 to flow over the plant, while a weaker stream flow under the plant (as seen from the

487 stream function contours). The average air velocity in the plant region varies between

$488 \quad 0.1-0.2 \mathrm{~m} / \mathrm{s}$, which perfectly suits plant growth conditions.

489

\subsection{Natural ventilation performance}

This sustainable GH will aim to rely on natural ventilation driven by two

mechanisms, namely the wind induced pressure field around the GH and the buoyancy

force induced by the warmer and more humid air in the GH riser. Natural ventilation is

493 effective if the outside temperature is low compared to GH riser air temperature, where

494 the difference in density between the inside and outside air causes natural draft [49].

495 Air temperature and humidity differences between the inside and outside of a GH produce forces that drive flow. The natural tendency for hot and humid air to rise and 

accumulate towards the upper part of a space leads to stable stratification, and this has a significant influence on the flow patterns within the GH. The determining factor in

499 the form of the vertical stratification is the location of the openings. The warm and

500 humid air will flow out over the upper area of the opening and the cool air will enter

501 through the lower area of the opening.

502 Buoyancy driven ventilation is significant only at low wind speeds. At low wind 503 speed, the buoyancy effect is the main driving force of ventilation in a GH with plant.

504 To evaluate the natural ventilation of this $\mathrm{GH}$, the temperature field on the inclined riser

505 generated by the four different air velocities is shown in Fig.11. During the day, the air 506 temperature at the inclined riser $\left(\mathrm{T}_{-} \mathrm{a} 6\right)$ is higher than the ambient air temperature at 507 wind speed of 0.3 and $0.4 \mathrm{~m} / \mathrm{s}$. At speed of $0.3 \mathrm{~m} / \mathrm{s}$, the air temperature at the inclined 508 riser is $4{ }^{\circ} \mathrm{C}$ higher than the ambient. This is due to the absorbed solar radiations by the 509 solar stills and dissipated subsequently as latent and sensible heat inside the GH. During

510 the non-solar hours, the outside air is warmer than the inside GH due to the cooling

511 effect created by the condenser. To achieve natural ventilation at night, the condenser

512 may have to be turned OFF. Hence, natural ventilation could be maintained in the GH

513 especially during the daytime. This conditions also satisfy the air exchange rate of 0.7 
$514 \quad \mathrm{AC} / \mathrm{min}$.

5153.6 Covering material parametric study

516 GH sustainability depends largely on cover material, as it influences the GH

517 microclimate and protect plants from adverse weather conditions. The evolution of

518 basic factors such as transmitted solar radiation, interior air temperature and water

519 production for each examined cover material are presented. Fig. 12a present the

520 instantaneous total solar radiation transmitted into the GH cavity for the examined

521 cover materials for the maximum radiation day of $21^{\text {st }}$ June. The highest transmitted

522 solar radiation is achieved with the glass and EVA cover, with 52 and $48 \%$ solar

523 radiation transmitted into the GH respectively. The PVC cover allows lower

524 transmittance $(\sim 30 \%)$ due to its high absorptivity, which may become less in winter

525 season. The air temperature and relative humidity differences inside the GH cavity for

526 the studied cover materials are not significant (data not shown), because the main

527 mechanism of heat transfer is from convection of the entering air stream and the effect

528 of air-cooling condenser. For water production, Fig. 12b shows the accumulated water

529 production for the examined cover materials. Less water is expected to be produced

530 from the transparent solar distillers for PVC and P.E covers due to high material 
531 absorptivity and low transmitted solar radiation. Although sufficient amount of fresh

532 water is expected to be produce from the air-cooling condenser unit.

\section{Conclusions}

534 In this study, a newly developed solar driven agricultural greenhouse for air cooling,

535 and solar energy application for irrigation water production is presented. The potentials

536 of using an integrated TSD-GH system was investigated, combining water production

537 and agricultural farming in the same area. The potential harmony between solar

538 radiation availability and the demand for irrigation water is illustrated. A new coupled

539 approach of MATLAB/Simulink and CFD modelling methodology was developed to

540 predict the performance of the sustainable GH system. This approach takes advantage

541 of the strength of each tool to study, with accuracy, the full functionality and

542 requirement needed to operate a sustainable GH integrated with solar desalination

543 system. The calculations are implemented for the external environmental condition of

$54421^{\text {st }}$ June, representing the maximum radiation day of Borg-El-Arab, Egypt.

545 In general, the excess solar radiation was utilized, allowing $8.5 \mathrm{MJ} / \mathrm{m}^{2}$.day of solar

546 intensity threshold for plant photosynthetic process. An AL-metal net was added to trap

547 the excess solar radiation for enhanced desalination water production. A parametric 
study was carried out to investigate the effect of different air flow velocity and covering

$550 \mathrm{~L} / \mathrm{m}^{2}$.day, and power consumption by $0.43 \mathrm{kWh} / \mathrm{m}^{2}$.day. At wind speed of $0.3 \mathrm{~m} / \mathrm{s}$, air

551 temperature at the inclined riser is $4{ }^{\circ} \mathrm{C}$ higher than the ambient condition. At this

552 condition, there is a tendency of the air to flow by natural draft, hence reducing the fan

553 power. At air velocity of $0.5 \mathrm{~m} / \mathrm{s}$ (base line), the average air temperature and relative

554 humidity in the $\mathrm{GH}$ cavity were $26^{\circ} \mathrm{C}$ and $62 \%$ respectively, at $12: 00$ of the maximum

555 radiation day. For different covering materials, the highest transmitted solar radiation

556 is achieved with glass and EVA cover, with 52 and $48 \%$ solar radiation transmitted into

557 the GH respectively.

In general, to overcome the MENA-GCC drought, this $\mathrm{GH}$ is designed to reach a water autonomous irrigation situation by investigating the potential of providing conventional and nonconventional water sources for a water efficient GH. This self-

561 sustainable GH will allow sufficient cooling to enable crop production in the extreme

562 summer climate of the Mediterranean regions. The proposed system will also allow

563 parallel production of food and water and enhance plant productivity. The desalination

564 components may perhaps enable regional progress in $\mathrm{GH}$ production into arid and 
565 MENA-GCC regions. In the next step of this research, a comprehensive economic

566 analysis and development of an experimental model are proposed. The economic

567 analysis will include the capital and operating cost of the integrated system. The major

568 capital cost will include building construction, cooling system, transparent solar

569 distillers, irrigation system, water storage tank, fan ventilation systems, lightening and

570 other machinery and equipment. Operational cost will consist of labor cost, material

571 input, marketing, fertilizer and repair and maintenance cost. The experimental

572 validation will be built along the shores of the Mediterranean Sea in Borg Al-Arab

573 Egypt, using cost effective and sustainable materials.

$574 \quad$ Declarations

$575 \quad$ Availability of data and materials

576 All data generated or analyzed during this study are available from the corresponding

577 author on reasonable request.

578 Competing interests

579 The authors have declared no conflict of interests.

$580 \quad$ Funding

581 This work was supported by Egypt-Japan University of Science and Technology. 
583 All authors read and approved the final manuscript.

\section{Acknowledgements}

585 The first author acknowledges Egyptian Ministry of Higher Education (MoHE) and

586 Japan International Cooperation Agency (JICA) for providing all the needed facilities

587 to conduct this research.

$588 \quad$ References

589 1. H. Esmaeli and R. Roshandel, "Optimal design for solar greenhouses based on climate conditions," Renew. Energy, vol. 145, pp. 1255-1265, 2020.

2. N. Shekarchi and F. Shahnia, "A comprehensive review of solar-driven desalination technologies for off-grid greenhouses,” Int. J. Energy Res., vol. 43, no. 4, pp. $1357-$ 1386, 2019. Huang, "Sustainable agriculture for water-stressed regions by air-water-energy management," Energy, vol. 181, pp. 1121-1128, 2019. 

Adv. Sci., vol. 5, no. 1, Jan. 2018.

605

6. J. I. Montero, E. J. Van Henten, J. E. Son, and N. Castilla, "Greenhouse engineering: New technologies and approaches," Acta Hortic., vol. 893, pp. 51-64, 2011.

608

7. G. Giacomelli, N. Castilla, E. Van Henten, D. Mears, and S. Sase, "Innovation in greenhouse engineering,” Acta Hortic., vol. 801 PART 1, no. July 2015, pp. 75-88, 2008.

611

8. G. L. Barbosa, F. D. Almeida Gadelha, N. Kublik, A. Proctor, L. Reichelm, E.

612 Weissinger, G. M. Wohlleb, and R. U. Halden, "Comparison of land, water, and

613 energy requirements of lettuce grown using hydroponic vs. Conventional 6891, Jun. 2015. 
616 9. R. H. E. Hassanien, M. Li, and W. Dong Lin, "Advanced applications of solar energy in agricultural greenhouses," Renewable and Sustainable Energy Reviews, vol. 54. Elsevier Ltd, pp. 989-1001, Feb-2016.

619

10. IRENA 2015 "Renewable Energy in the Water, Energy \& Food Nexus"

620 11. J. J. Cartelle Barros, M. Lara Coira, M. P. de la Cruz López, and A. del Caño Gochi,

621 "Assessing the global sustainability of different electricity generation systems," 622 Energy, vol. 89, pp. 473-489, Sep. 2015.

623 12. G. K. Ntinas, V. P. Fragos, and C. Nikita-Martzopoulou, "Thermal analysis of a 624 vol. 81, pp. 428-439, 2014.

626

13. A. M. Syed and C. Hachem, "Review of Design Trends in Lighting, Environmental Controls, Carbon Dioxide Supplementation, Passive Design, and Renewable Energy Systems for Agricultural Greenhouses,” J. Biosyst. Eng., vol. 23, no. 1, pp. 28-36, 2019.

630 14. A. Yano, A. Furue, M. Kadowaki, T. Tanaka, E. Hiraki, M. Miyamoto, F. Ishizu, and S. Noda, "Electrical energy generated by photovoltaic modules mounted inside the roof of a north-south oriented greenhouse," Biosyst. Eng., vol. 103, no. 2, pp. 
634 15. A. Al-Ibrahim, N. Al-Abbadi, and I. Al-Helal, "PV greenhouse system - System description, performance and lesson learned," Acta Hortic., vol. 710, pp. 251-264, 2006. greenhouses in hot and arid environments - A review," Engineering in Agriculture, Environment and Food, vol. 12, no. 1. Elsevier B.V., pp. 48-70, Jan-2019.

641 17. A. Marucci and A. Cappuccini, "Dynamic photovoltaic greenhouse: Energy efficiency in clear sky conditions,” Appl. Energy, vol. 170, pp. 362-376, May 2016. "Advances on the semi-transparent modules based on micro solar cells: First integration in a greenhouse system," Appl. Energy, vol. 162, pp. 1042-1051, Jan. 2016. “Optimum operational performance of a new stand-alone agricultural greenhouse with integrated-TPV solar panels,” Sol. Energy, vol. 136, pp. 303-316, 2016. 
650

651

652

653

654

655

656

657

658

659

660

661

662

663

664

665

666

20. A. Yano, M. Onoe, and J. Nakata, "Prototype semi-transparent photovoltaic modules for greenhouse roof applications," Biosyst. Eng., vol. 122, pp. 62-73, 2014.

21. T. Yohannes and H. Fath, "Novel Agriculture Greenhouse That Grows Its Water And Power : Thermal Analysis," Cancam, 2013.

22. H. E. S. Fath and K. Abdelrahman, "Micro-climatic environmental conditions inside a greenhouse with a built-in solar distillation system," vol. 171, pp. 267-287, 2004.

23. A. A. M. Radhwan, “Transient performance of a stepped solar still with built-in latent heat thermal energy storage," Desalination, vol. 171, no. 1, pp. 61-76, 2005.

24. M. T. Chaibi, "Validation of a simulation model for water desalination in a greenhouse roof through laboratory experiments and conceptual parameter discussions," Desalination, vol. 142, no. 1, pp. 65-78, Jan. 2002.

25. E. G. Mari, R. P. G. Colomer, and C. A. Blaise-Ombrecht, "Performance analysis of a solar still integrated in a greenhouse," Desalination, vol. 203, no. 1-3, pp. 435443, 2007.

26. A. Radhwan and H. E. S. Fath, "Thermal Performance of Greenhouse with Built-in Solar Distillation System: Experimental Study," Ninth Int. Water Technol. Conf., 
pp. 793-809, 2005.

27. A. H. Salah, G. E. Hassan, H. Fath, M. Elhelw, and S. Elsherbiny, "Analytical investigation of different operational scenarios of a novel greenhouse combined with solar stills,” Appl. Therm. Eng., vol. 122, pp. 297-310, 2017.

28. O. O. Rabhy, I. G. Adam, M. Elsayed Youssef, A. B. Rashad, and G. E. Hassan, agricultural greenhouse,” Appl. Energy, vol. 253, no. July, p. 113564, 2019.

29. H. J. J. Janssen, T. H. Gieling, S. L. Speetjens, J. D. Stigter, and G. Van Straten, "Watergy: Infrastructure for process control in a closed greenhouse in semi-arid

30. H. F. De Zwart, “The sunergy greenhouse - One year of measurements in a next generation greenhouse," in Acta Horticulturae, 2011, vol. 893, pp. 351-358.

31. A. M. Al-Ismaili and H. Jayasuriya, "Seawater greenhouse in Oman: A sustainable technique for freshwater conservation and production," Renewable and Sustainable Energy Reviews, vol. 54. Elsevier Ltd, pp. 653-664, Feb-2016. 
water- and energy-self-sufficient agriculture,” Appl. Energy, vol. 187, pp. 390-409,

685 2017.

686

33. C. B. Maia, F. V. M. Silva, V. L. C. Oliveira, and L. L. Kazmerski, “An overview of the use of solar chimneys for desalination," Sol. Energy, vol. 183, pp. 83-95, 2019.

689

34. P. Amarananwatana and C. Sorapipatana, "An Assessment of the ASHRAE Clear Sky Model for Irradiance Prediction in Thailand Nuntiya," Asian J. Energy Environ,

691 vol. 08 , no. 02 , pp. 523-532, 2007.

35. S. Rabia, 2017 ASHRAE Handbook Fundamentals SI.pdf. .

693

36. Abdullahi, K., Salah, A.H., Fath, H.E.S., 2019. Transient operational performance of integrated solar greenhouse - Desalination system: Case study of Mediterranean mild winter condition. p. 030006. https://doi.org/10.1063/1.5117037

37. D. Piscia, J. I. Montero, E. Baeza, and B. J. Bailey, “A CFD greenhouse night-time 697 condensation model," Biosyst. Eng., vol. 111, no. 2, pp. 141-154, 2012.

698

38. I. Janajreh, H. E. S. Fath, and S. S. Raza, "Thermal performance of solar-distillation

699 integrated greenhouses," 2012.

39. D. Piscia, P. Muñoz, C. Panadès, and J. I. Montero, “A method of coupling CFD 
and energy balance simulations to study humidity control in unheated greenhouses,"

40. T. Boulard and S. Wang, "Greenhouse crop transpiration simulation from external climate conditions," vol. 100, pp. 25-34, 2000.

705

41. J. Chen, F. Xu, D. Tan, Z. Shen, L. Zhang, and Q. Ai, “A control method for agricultural greenhouses heating based on computational fluid dynamics and energy prediction model," Appl. Energy, vol. 141, no. 1, pp. 106-118, 2015.

43. C. Baxevanou, D. Fidaros, T. Bartzanas, and C. Kittas, "Yearly numerical evaluation of greenhouse cover materials," Comput. Electron. Agric., vol. 149, no. August 2016, pp. 54-70, 2018. optimization of solar greenhouse with removable back walls based on CFD," Comput. Electron. Agric., no. October, pp. 0-1, 2017. 
718 46. W. Baudoin, R. Nono-Womdim, "Good agricultural practices for greenhouse

719 vegetable crops: Principles for mediterranean climate areas,” agris.fao.org.

720 47. A. H. Salah and G. E. Hassan, "Performance Improvement of Roof Transparent

721 Solar Still Coupled With Agriculture Greenhouse,” Int. Conf. New Trends Sustain.

722 Energy-ICNTSE, vol. 3, no. 1, pp. 151-154, 2016.

723 48. N. Katsoulas, A. Sapounas, F. De Zwart, J. A. Dieleman, and C. Stanghellini, 724 "Reducing ventilation requirements in semi-closed greenhouses increases water use 725 efficiency,” Agric. Water Manag., vol. 156, pp. 90-99, 2015.

726 49. C. R. Chu, T. W. Lan, R. K. Tasi, T. R. Wu, and C. K. Yang, "Wind-driven natural 727 ventilation of greenhouses with vegetation,” Biosyst. Eng., vol. 164, pp. 221-234, $728 \quad 2017$. 


\begin{tabular}{|c|c|c|c|}
\hline \multicolumn{4}{|c|}{ Nomenclature } \\
\hline$A$ & apparent solar irradiation & $a$ & mean height of plants \\
\hline$B_{c}$ & breadth of channel, $\mathrm{m}$ & $C$ & diffuse radiation factor \\
\hline$C_{2}$ & inertial resistance & $C O P$ & Coefficient of Performance \\
\hline$C_{p}$ & specific heat, $\mathrm{J} / \mathrm{kg} \mathrm{K}$ & $\mathrm{D}_{\mathrm{H} 2 \mathrm{O}}$ & vapor-air diffusion \\
\hline$e$ & Total fluid energy & $H_{S}$ & height of south wall, $\mathrm{m}$ \\
\hline$H_{N}$ & height of north wall, $\mathrm{m}$ & $h_{f g}$ & heat of vaporization of water, $\mathrm{J} / \mathrm{kg}$ \\
\hline$h_{j}$ & Sensible enthalpy & $h_{w}$ & height of water in the TSD, $\mathrm{m}$ \\
\hline$h_{\text {out }}$ & enthalpy of outlet air, $\mathrm{J} / \mathrm{kg}$ & $h_{\text {in }}$ & enthalpy of inlet air, $\mathrm{J} / \mathrm{kg}$ \\
\hline$I_{B \beta}$ & direct beam solar radiation, $\mathrm{W} / \mathrm{m}^{2}$ & $I_{\beta}$ & incident global solar radiation, $\mathrm{W} / \mathrm{m}^{2}$ \\
\hline$I_{D \beta}$ & diffused solar radiation, $\mathrm{W} / \mathrm{m}^{2}$ & $I_{R \beta}$ & reflected radiation $\mathrm{W} / \mathrm{m}^{2}$ \\
\hline K & thermal conductivity & $k$ & atmospheric extinction coefficient \\
\hline$L_{b}$ & Length of TSD base, $\mathrm{m}$ & $L A I$ & leaf area index \\
\hline$L$ & length of the greenhouse, $\mathrm{m}$ & $k_{p}$ & plant leaf Characteristic length, $\mathrm{m}$ \\
\hline$M$ & Mass, $\mathrm{kg}$ & $m_{a}$ & mass flow rate of air, $\mathrm{kg} / \mathrm{s}$ \\
\hline$m_{c}$ & mass flow rate of water, $\mathrm{kg} / \mathrm{s}$ & $m_{\text {cond }}$ & mass flow rate of air through the condenser, $\mathrm{kg} / \mathrm{s}$ \\
\hline $\operatorname{Pr}_{t}$ & Prandtl number & $Q_{e}$ & Evaporated heat, $\mathrm{W}$ \\
\hline$Q_{i n}$ & inlet heat to any component & $Q_{\text {out }}$ & outlet heat from any component \\
\hline$r_{a}$ & plant aerodynamic resistance, $\mathrm{s} / \mathrm{m}$ & $r_{s}$ & plant stomata resistance, $\mathrm{s} / \mathrm{m}$ \\
\hline$S$ & Source term & $S c_{t}$ & Schmidt number \\
\hline$S_{h}$ & horizontal space between TSDs, $\mathrm{m}$ & $S_{r}$ & vertical space between TSDs, $m$ \\
\hline
\end{tabular}




\begin{tabular}{|c|c|c|c|}
\hline$S_{i}$ & Momentum sink & $T$ & Temperature \\
\hline$t h_{g}$ & thickness of glass, $m$ & $u_{i}$ & Air velocity \\
\hline$\vec{V}$ & Velocity vector & $W$ & Width of greenhouse \\
\hline$w$ & Absolute humidity, $\mathrm{kg}$ (water) $/ \mathrm{kg}$ (air) & $x_{i}$ & Cartesian coordinate \\
\hline$\alpha$ & Absorptivity & $\mathrm{YH}_{\mathrm{H} 2 \mathrm{O}}$ & Specie concentration \\
\hline$\beta$ & GH roof tilted angle & $\varepsilon$ & Emissivity \\
\hline$\rho$ & Density, $\mathrm{kg} / \mathrm{m}^{3}$ & $\nabla$ & Divergence operator \\
\hline$\Gamma$ & Diffusion coefficient & $\tau$ & Transmissivity \\
\hline$\psi$ & Latitude angle & $\mu_{t}$ & Turbulent viscosity \\
\hline$p$ & Plant & $\phi$ & Concentration variable \\
\hline$\omega$ & Azimuthal angle & $g r$ & Ground \\
\hline$\theta_{z}$ & Zenith angle on an inclined surface & $a_{i}$ & Circulating air in the GH cavity \\
\hline$a_{2}$ & Exit of condenser & $\delta$ & Declination angle \\
\hline
\end{tabular}

731

732

733

734

Table 1. Greenhouse geometrical dimensions.

\begin{tabular}{llll}
\hline$L$ & $8(\mathrm{~m})$ & $\beta_{\mathrm{TSD}}$ & $30^{\circ}$ \\
\hline$W$ & $1(\mathrm{~m})$ & $L_{b}$ & $0.75(\mathrm{~m})$ \\
$H_{S}$ & $2.5(\mathrm{~m})$ & $h_{w}$ & $1(\mathrm{~cm})$ \\
$H_{N}$ & $4.5(\mathrm{~m})$ & $S_{h}$ & $0.5(\mathrm{~m})$ \\
$B_{c}$ & $1.5(\mathrm{~m})$ & $S_{r}$ & $0.75(\mathrm{~m})$ \\
$t h_{g}$ & $3(\mathrm{~mm})$ & & \\
\hline
\end{tabular}


Table 2. CFD parameters used.

\begin{tabular}{|c|c|c|c|}
\hline CLASSIFICATION & METHOD & $\begin{array}{l}\text { Under relaxation } \\
\text { factor }\end{array}$ & $\begin{array}{l}\text { Paramete } \\
\text { r }\end{array}$ \\
\hline Solver settings & $\begin{array}{l}\text { Pressure-based } \\
\text { solver }\end{array}$ & Pressure & 0.3 \\
\hline $\begin{array}{l}\text { Pressure-Velocity } \\
\text { Coupling }\end{array}$ & SIMPLE & Density & 1 \\
\hline Energy discrete scheme & $\begin{array}{l}\text { Second order } \\
\text { upwind }\end{array}$ & Mass Force & 0.9 \\
\hline $\begin{array}{l}\text { Momentum discrete } \\
\text { scheme }\end{array}$ & $\begin{array}{l}\text { Second order } \\
\text { upwind }\end{array}$ & Momentum & 0.7 \\
\hline $\mathrm{k}$ discrete scheme & First order upwind & $\mathrm{H}_{2} \mathrm{O}$ & 1 \\
\hline e discrete scheme & First order upwind & Energy & 1 \\
\hline \multirow[t]{2}{*}{$\mathrm{H}_{2} \mathrm{O}$ scheme } & $\begin{array}{l}\text { Second } \\
\text { upwind }\end{array}$ & Turbulent Viscosity & 1 \\
\hline & & $\mathrm{k}$ and $\mathrm{e}$ & 0.8 \\
\hline
\end{tabular}


Table 3. Plant parameters.

\begin{tabular}{llll}
\hline$a$ & $1(\mathrm{~m})$ & $L A I$ & 3 \\
\hline$C_{p, p}$ & $2130(\mathrm{~J} / \mathrm{kg} . \mathrm{k})$ & $\alpha_{p}$ & 0.4 \\
$\varepsilon_{p}$ & 0.92 & $\rho_{p}$ & $700\left(\mathrm{~kg} / \mathrm{m}^{3}\right)$ \\
$k_{p}$ & $0.173(\mathrm{~W} / \mathrm{m} . \mathrm{K})$ & $L_{p}$ & $0.03(\mathrm{~m})$ \\
$r_{a}$ & 50 (day) to 5000(night) $(\mathrm{S} / \mathrm{m})$ & $r_{s}$ & $250(\mathrm{~S} / \mathrm{m})$ \\
\hline
\end{tabular}

739

740

741

742

743

744 
Table 4. Thermo-physical material parameters.

\begin{tabular}{llllll}
\hline Glass & \multicolumn{3}{c}{ Water } & \multicolumn{2}{c}{ GROUND } \\
\hline$\varepsilon_{g}$ & 0.92 & $\mathcal{E}_{w}$ & 0.4733 & $\mathcal{E}_{g r}$ & 0.93 \\
$\alpha_{g}$ & 0.06 & $\alpha_{w}$ & 0.3 & $\alpha_{g r}$ & 0.4 \\
$\tau_{g}$ & 0.9 & $\tau_{\mathrm{W}}$ & 0.68 & $\tau_{\mathrm{gr}}$ & $1\left(\mathrm{~W} / \mathrm{m}^{2} . \mathrm{K}\right)$ \\
$\rho_{g}$ & $2500\left(\mathrm{~kg} / \mathrm{m}^{3}\right)$ & $\rho_{w}$ & $1\left(\mathrm{Ton} / \mathrm{m}^{3}\right)$ & $\rho_{g r}$ & $1680\left(\mathrm{~kg} / \mathrm{m}^{3}\right)$ \\
$C_{p, g}$ & $750(\mathrm{~J} / \mathrm{kg} . \mathrm{k})$ & $C_{p, w}$ & $4186(\mathrm{~J} / \mathrm{kg} \cdot \mathrm{k})$ & $C_{p, g r}$ & $1187.8 \quad(\mathrm{~J} / \mathrm{kg}$. \\
& & & & & $\mathrm{k})$ \\
$K_{g}$ & $1.2(\mathrm{~W} / \mathrm{m} . \mathrm{K})$ & & & $K_{g r}$ & $2.15(\mathrm{~W} / \mathrm{m} . \mathrm{K})$ \\
\hline
\end{tabular}

746

747

748

749

750

751

752

753

754

755

756

757

758

759

760

761

762

763 
Table 5. Material's thermal and optical properties.

\begin{tabular}{lllll}
\hline Material & Glass & P.E & EVA & PVC film \\
\hline Density $\rho\left[\mathbf{k g ~ m}^{-\mathbf{3}}\right]$ & 2500 & 923 & 926 & 900 \\
Specific heat $\boldsymbol{C}_{\boldsymbol{p}}\left[\mathbf{J} \mathbf{~ k g}^{-\mathbf{1}} \mathbf{K}^{-}\right.$ & 750 & 2300 & 2600 & 2550 \\
$\mathbf{1}]$ & & & & \\
Emissivity & 0.92 & 0.7 & 0.89 & 0.91 \\
Absorptivity & 0.06 & 0.1 & 0.02 & 0.1 \\
Transmissivity & 0.9 & 0.85 & 0.89 & 0.8 \\
\hline
\end{tabular}

765

766 
Figures

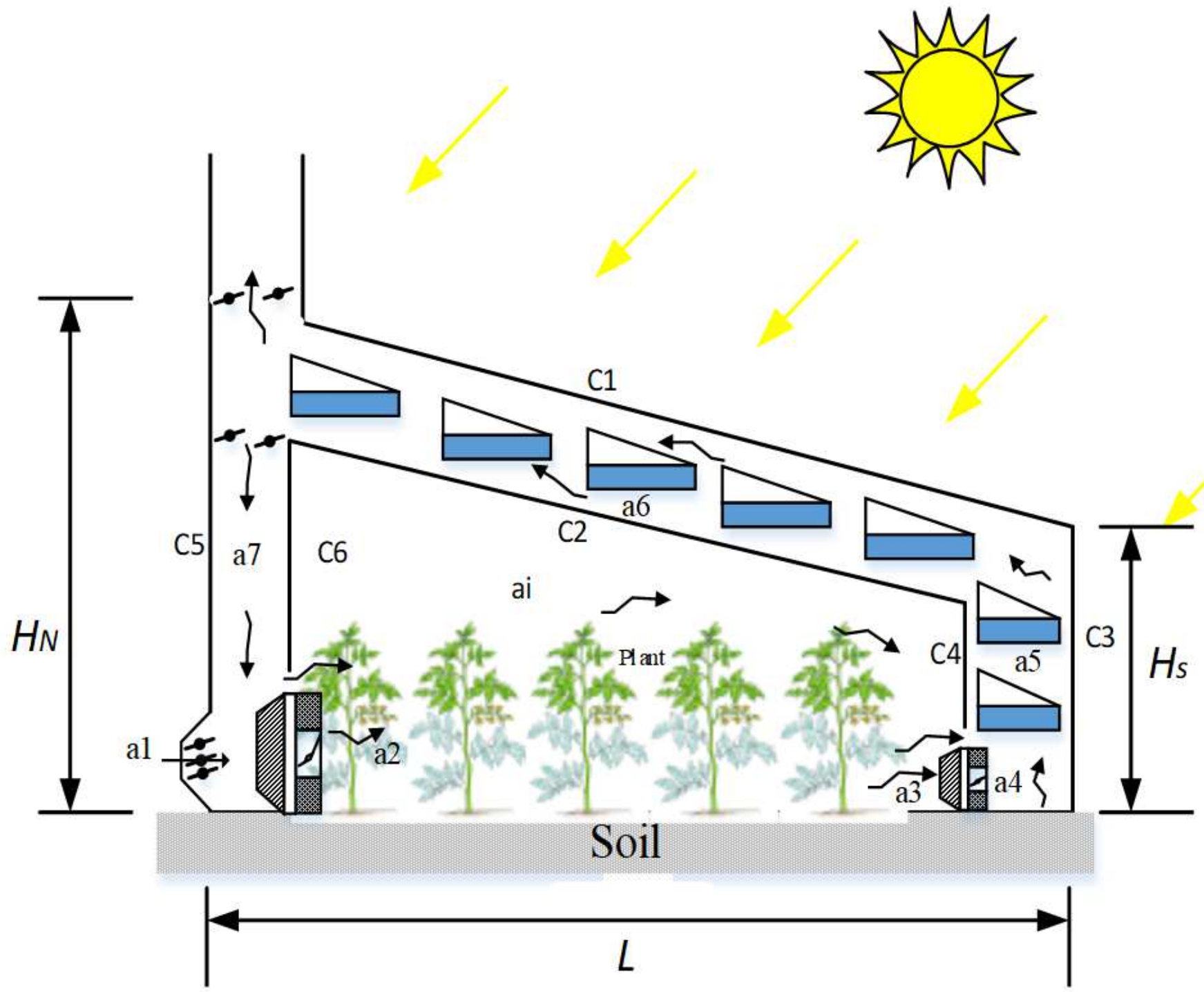

Figure 1

Conceptual configuration of the developed greenhouse. 
Condensing glass cover

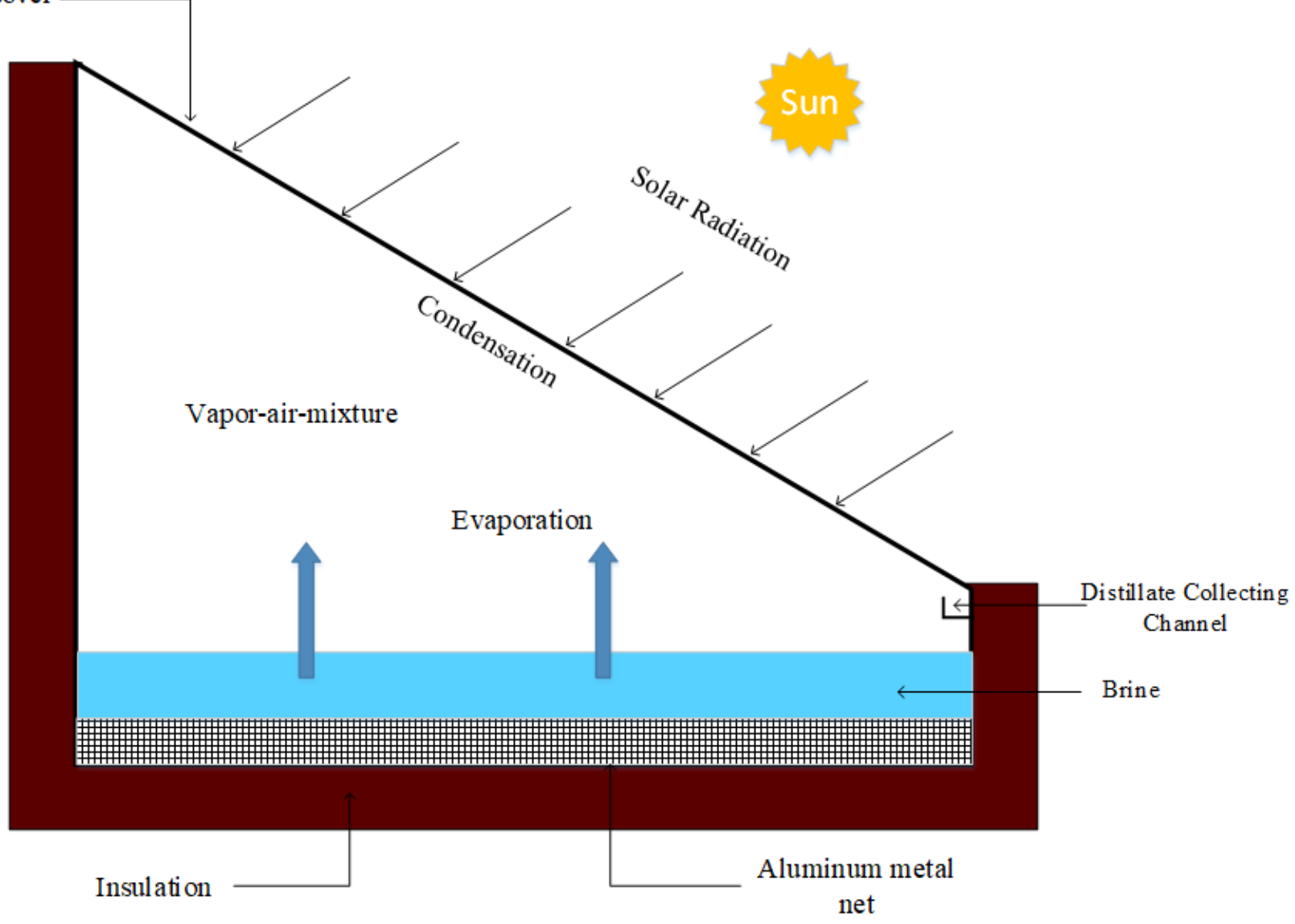

Figure 2

Simple configuration of the transparent solar distillers integrated into the greenhouse roof.

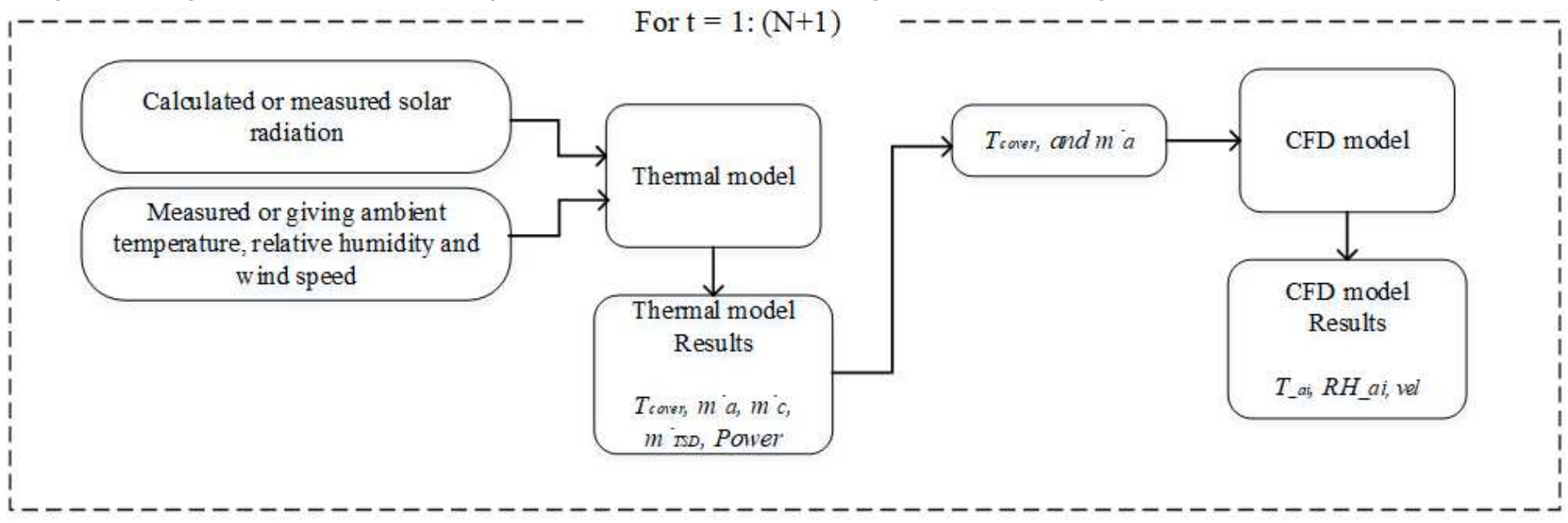

\section{Figure 3}

Brief description of the system methodology. 


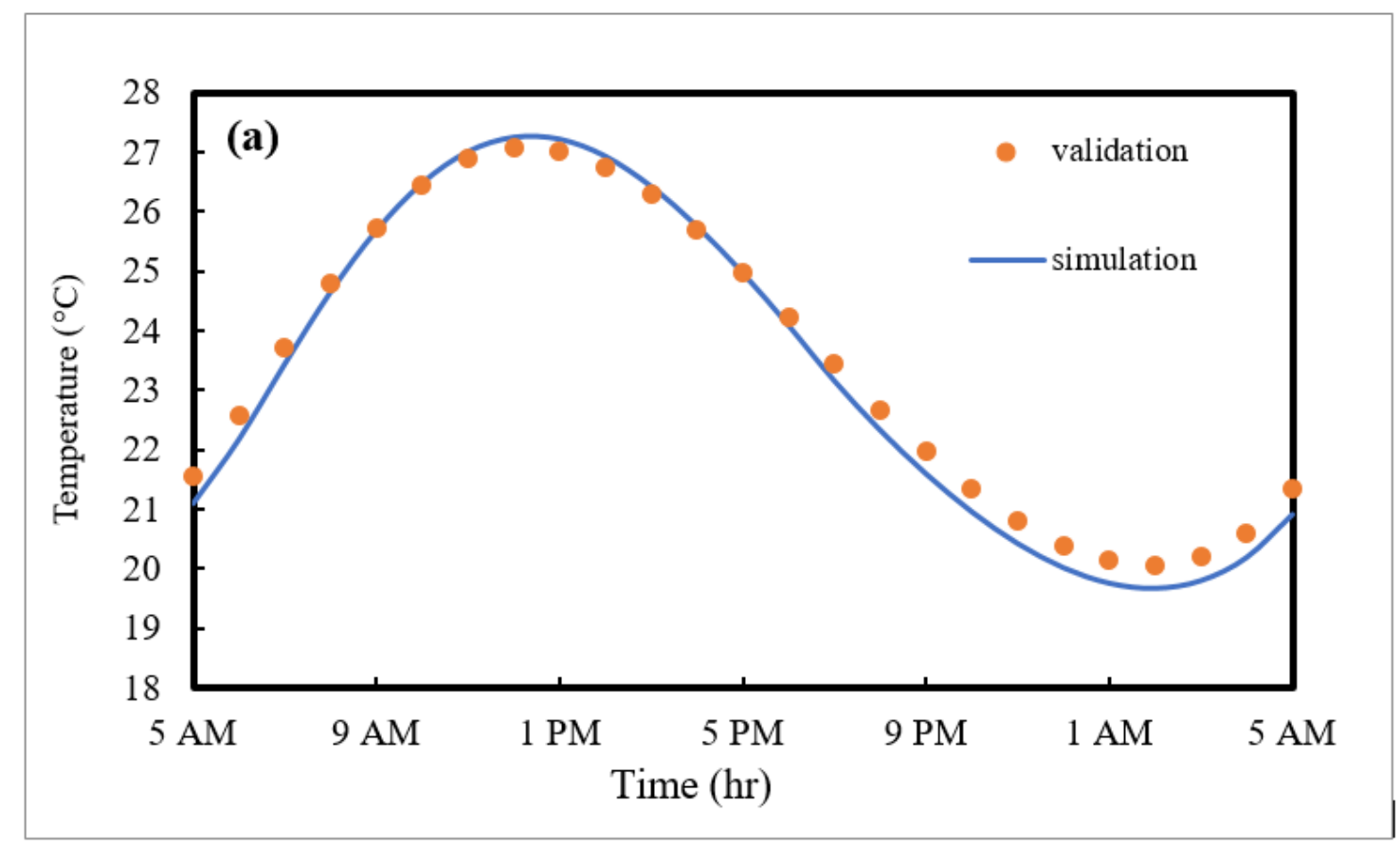

(a) Temperature

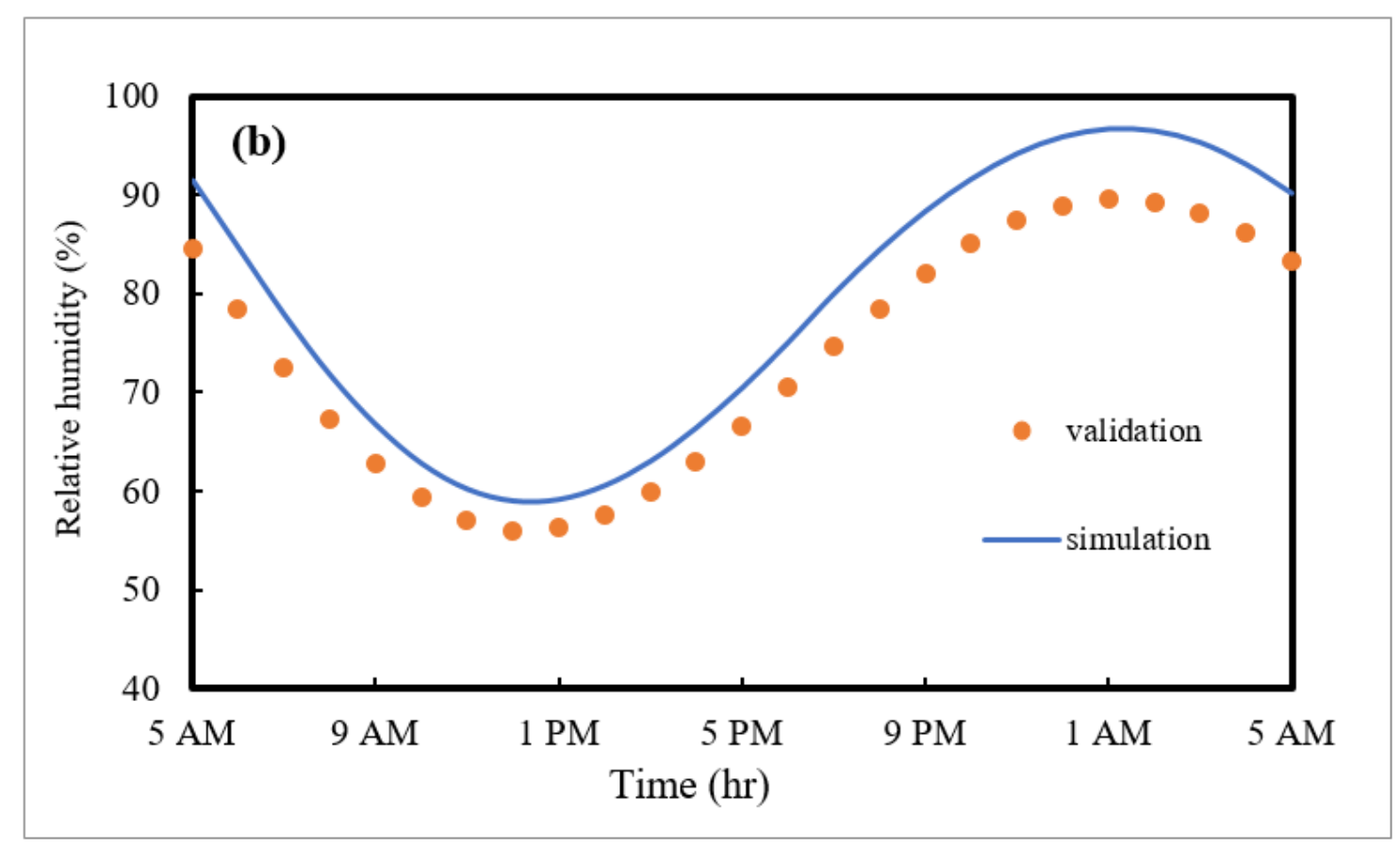

(b) Relative humidity

Figure 4

CFD numerical and validation results of the greenhouse air temperature (a) and relative humidity (b) for a typical day of June. 


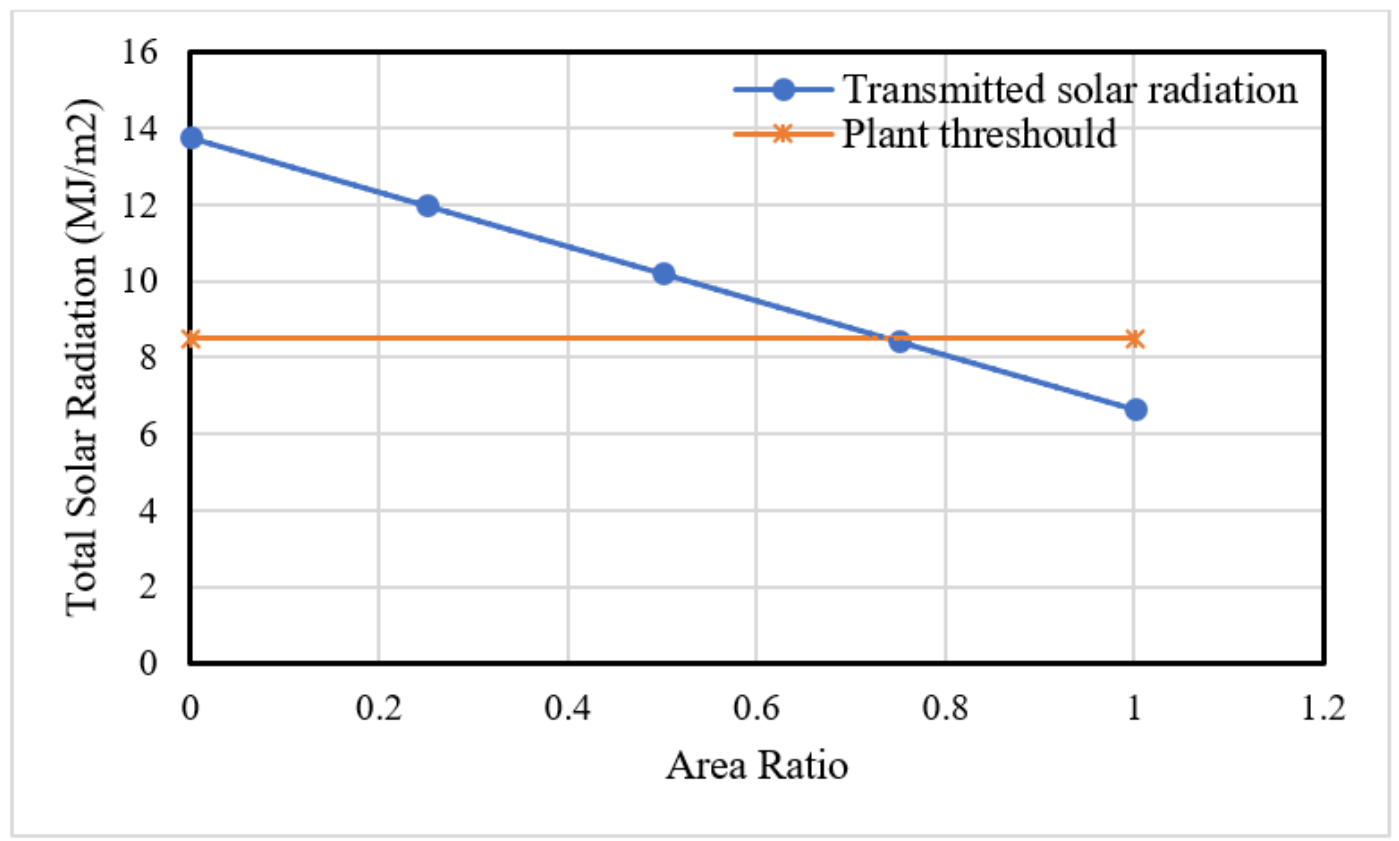

(a) Effect of Al-metal net area ratio on the total solar radiation transmitted into the GH cavity.

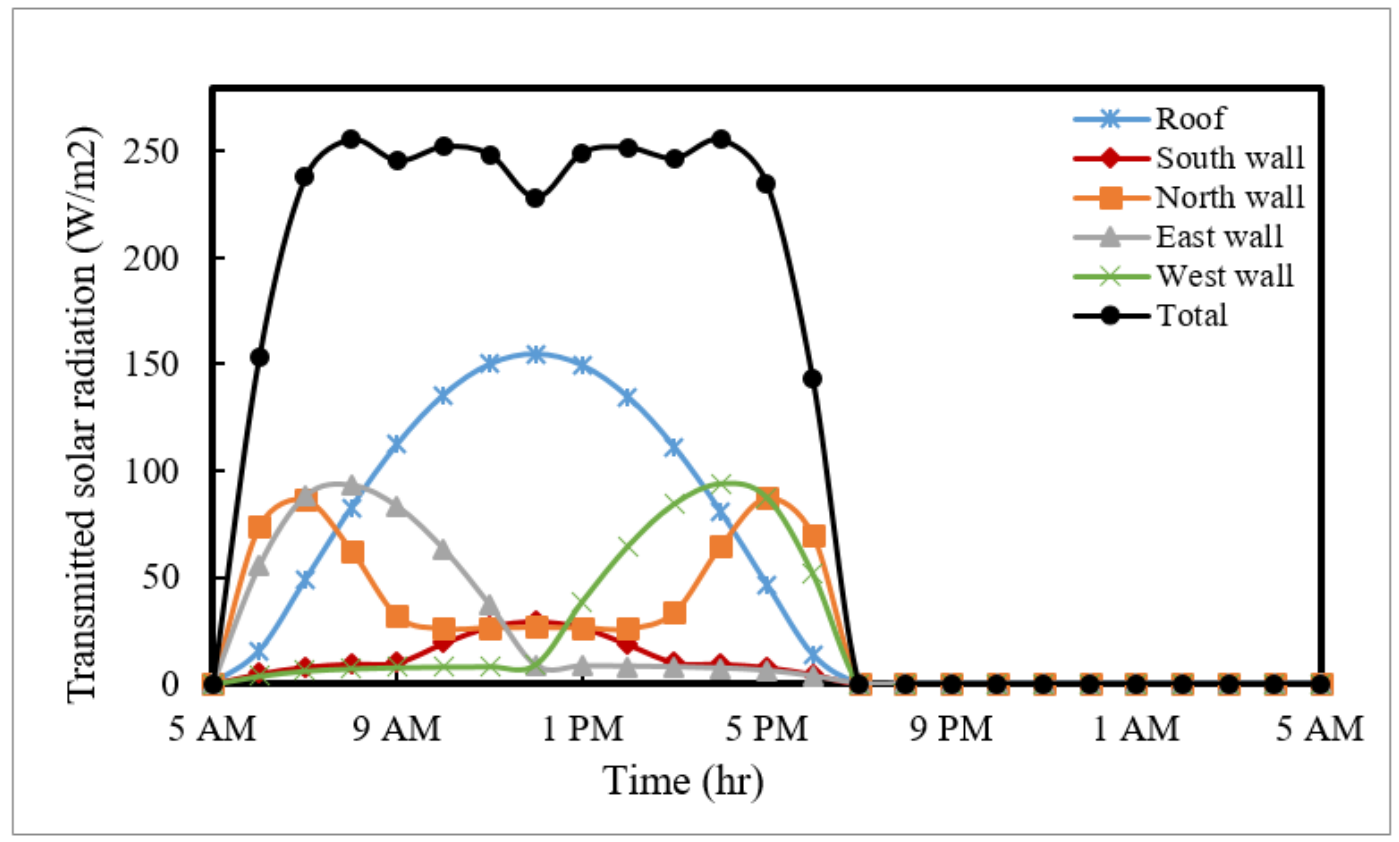

(b) Instantaneous solar radiation transmitted through the roof and walls of the GH

\section{Figure 5}

Effect of Al-metal net area ratio and instantaneous solar radiation transmitted into the greenhouse for a typical day of 21 st June. 


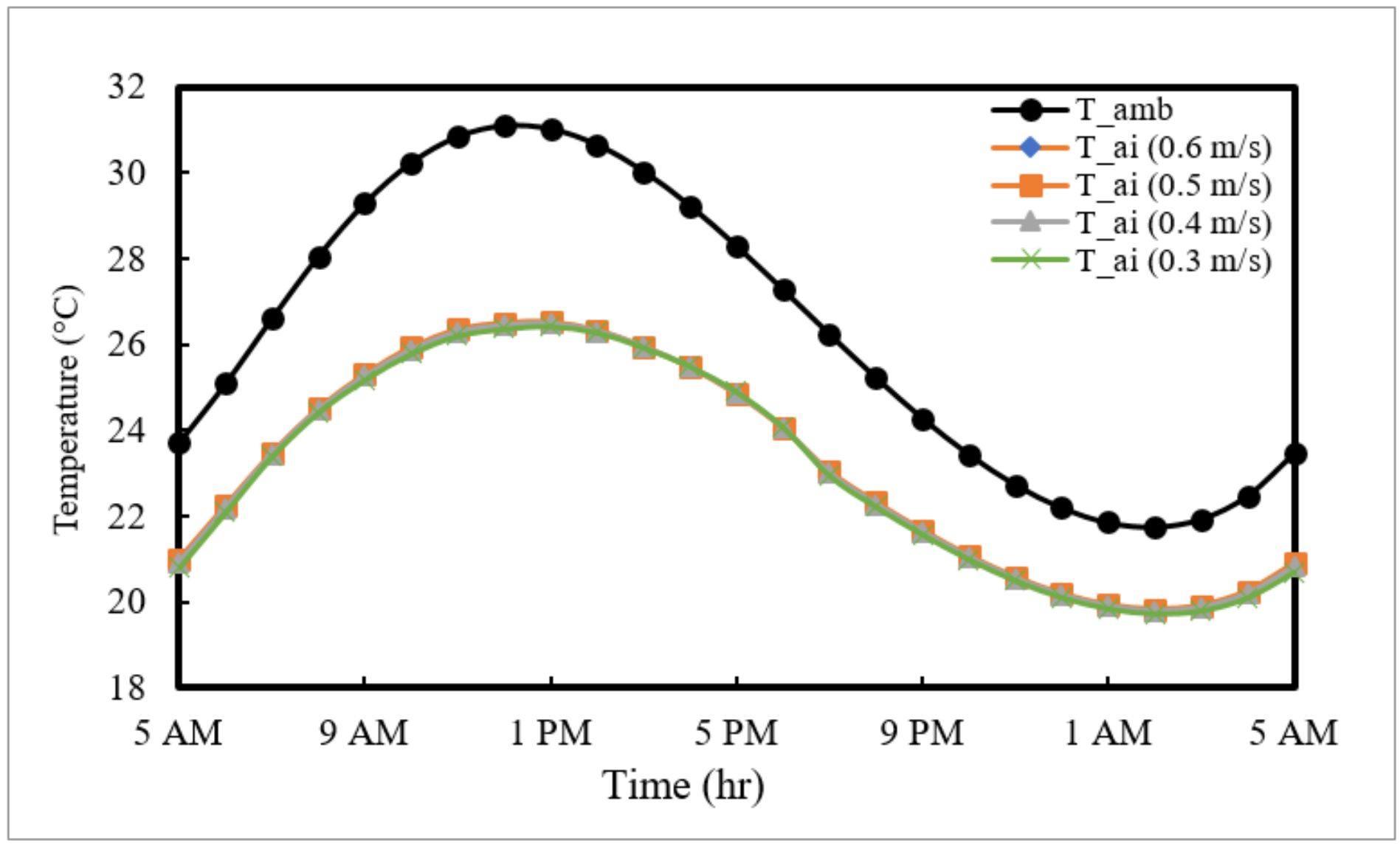

Figure 6

Instantaneously air temperature inside the greenhouse cavity at different air velocity for a typical day of 21st June in Borg AL-Arab Egypt. 


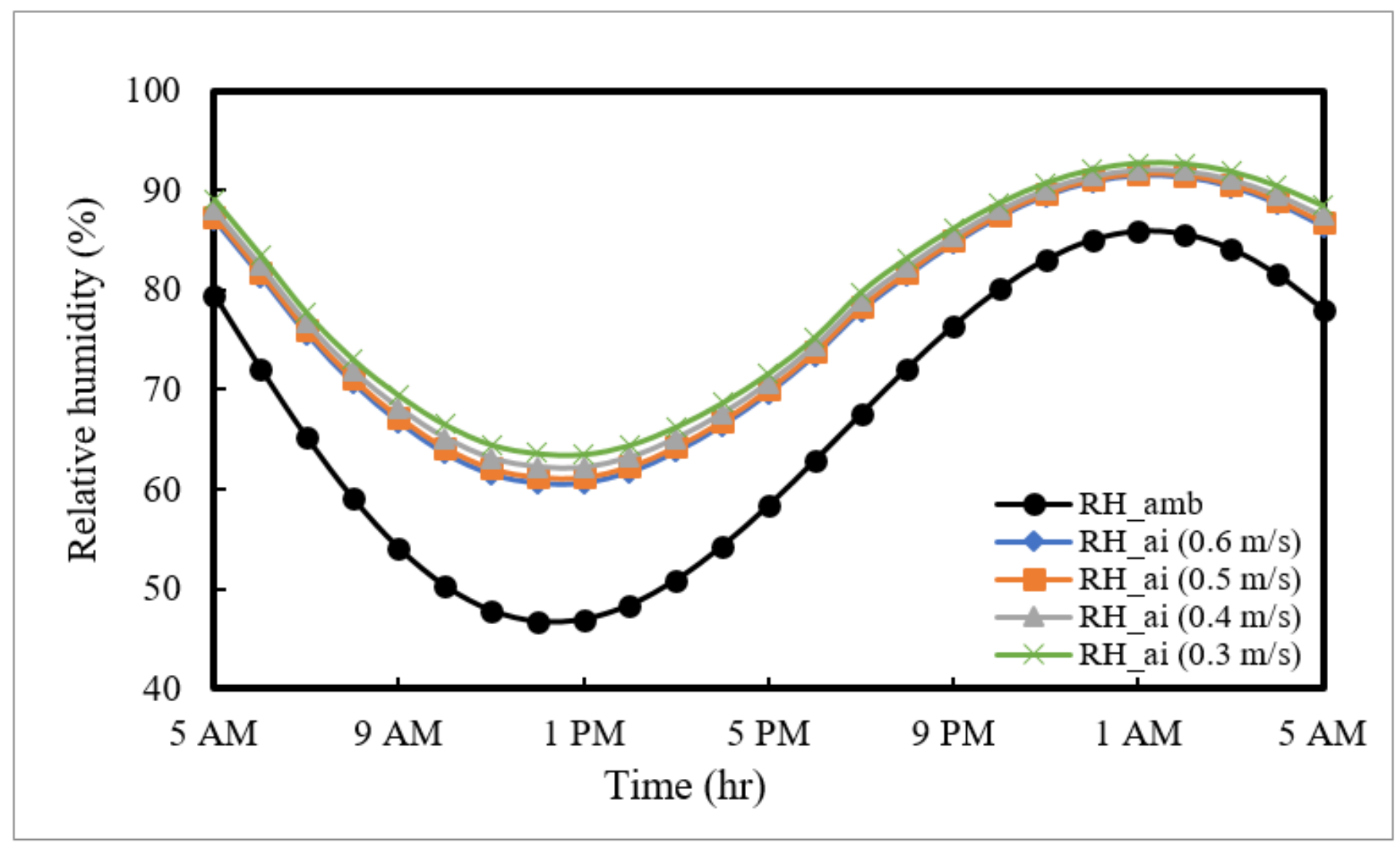

Figure 7

Instantaneously air relative humidity inside the greenhouse cavity at different air velocity for a typical day of 21st June in Borg AL-Arab Egypt. 


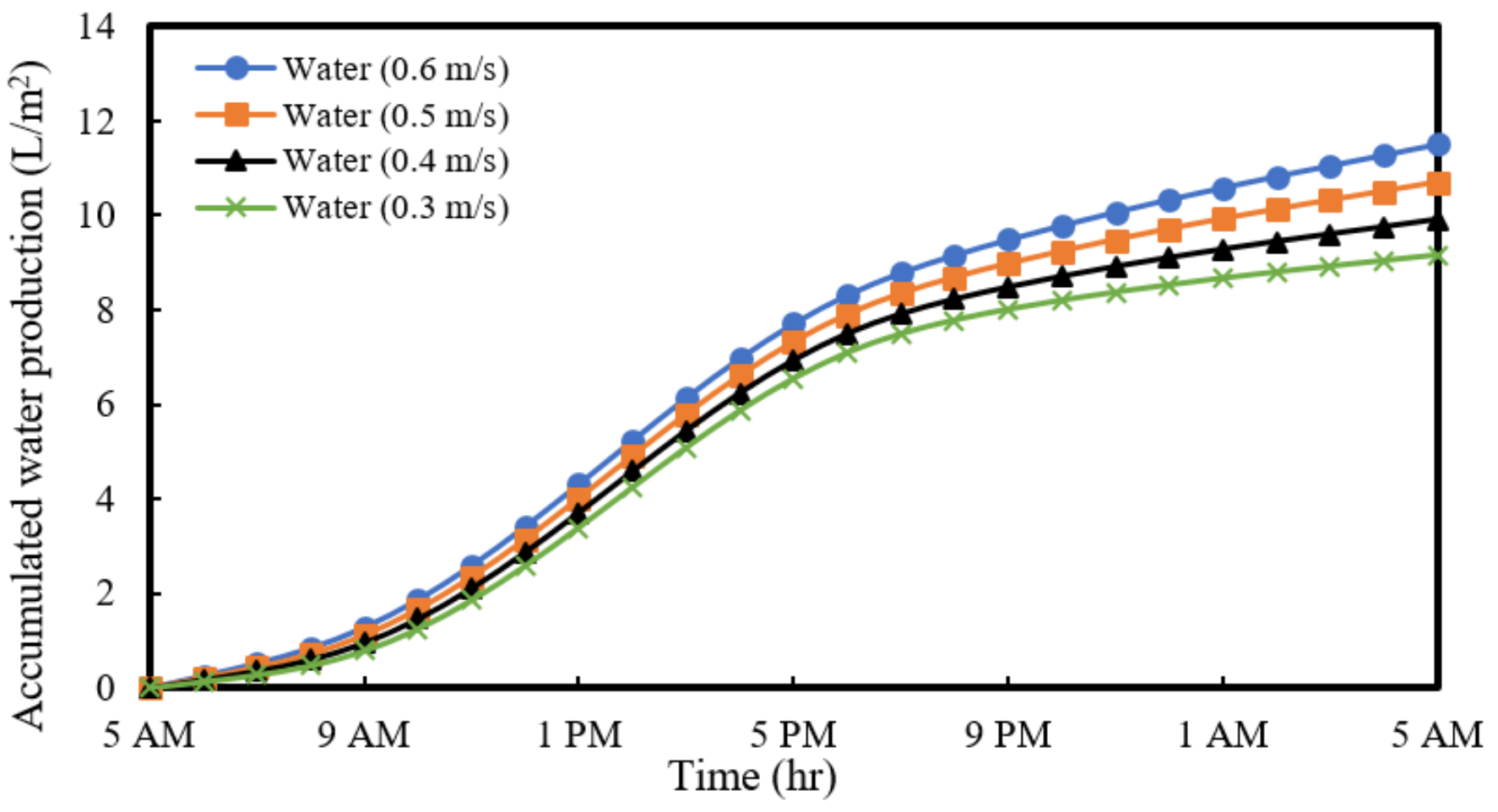

Figure 8

Accumulated water production at different air flow velocities for a typical day of 21 st June in Borg ALArab Egypt. 


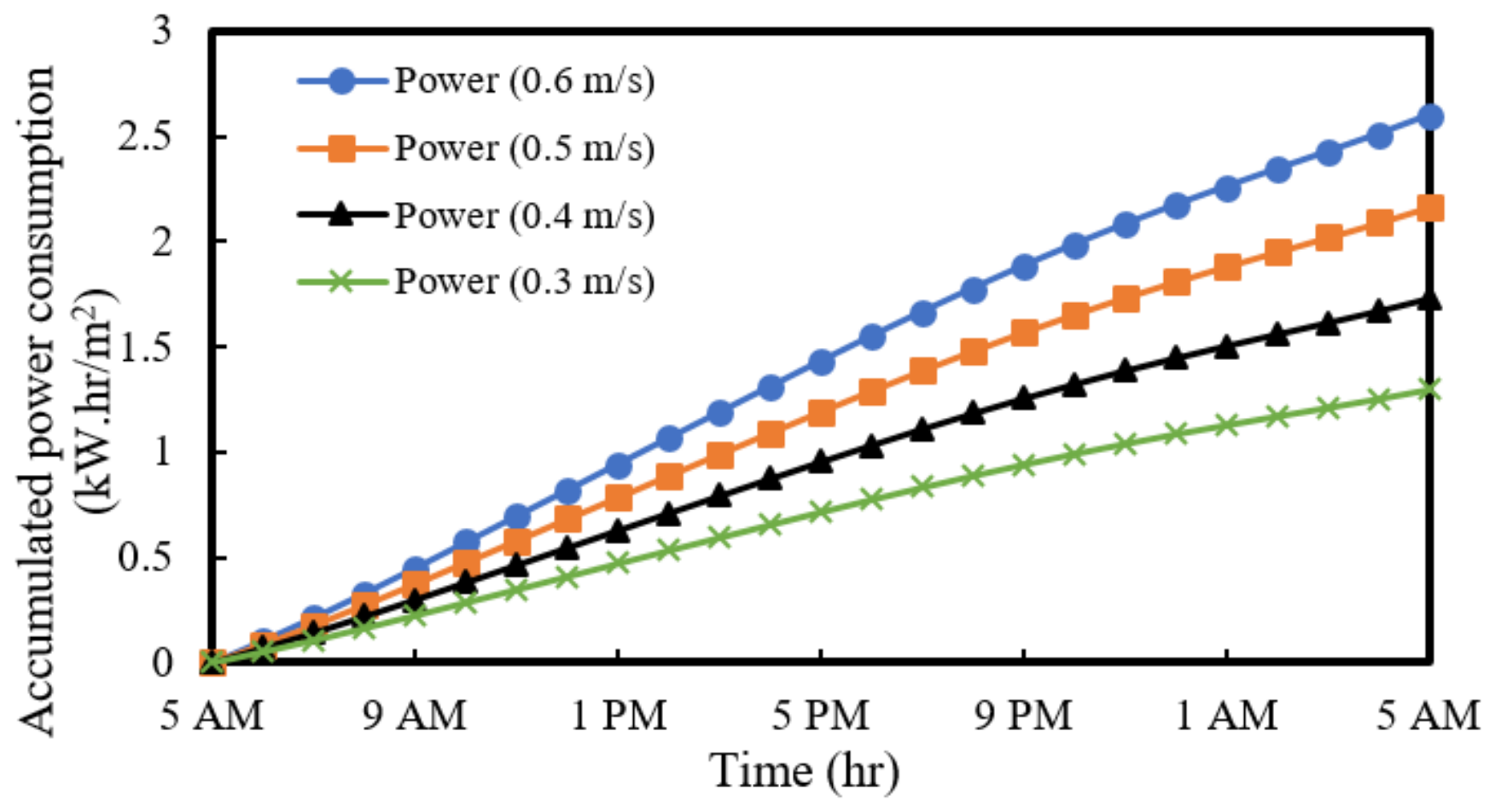

Figure 9

Accumulated power consumption at different air flow velocities for a typical day of 21 st June in Borg ALArab Egypt. 


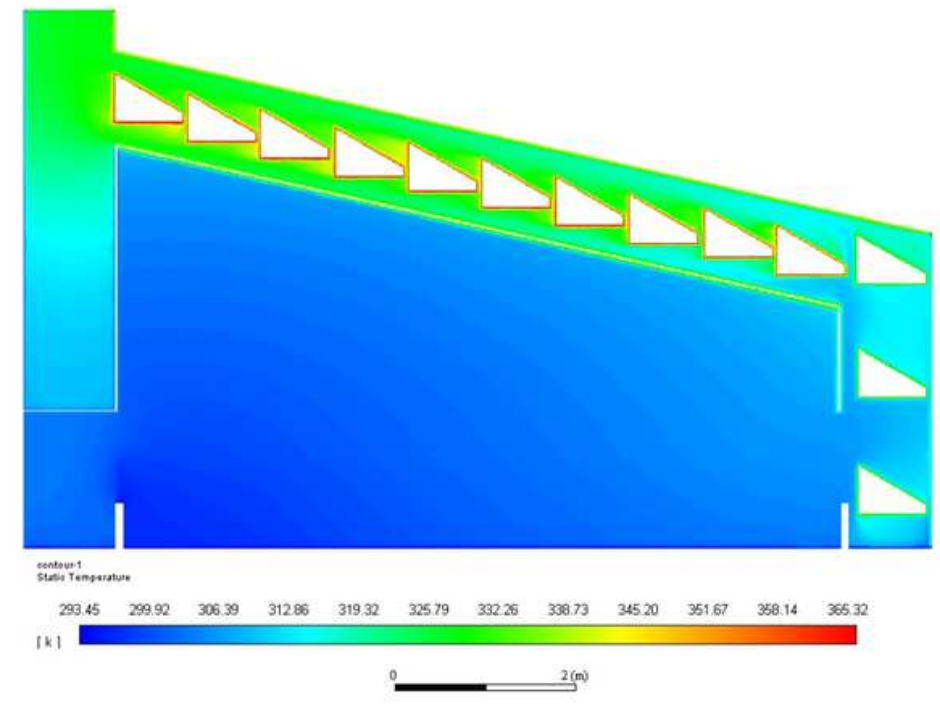

(a) Air temperature contours

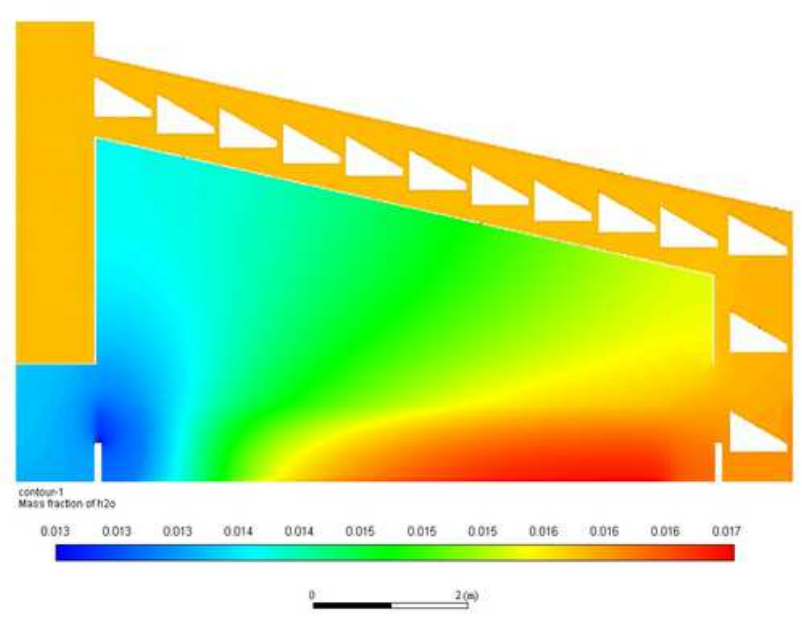

(c) Water vapor mass fraction contours

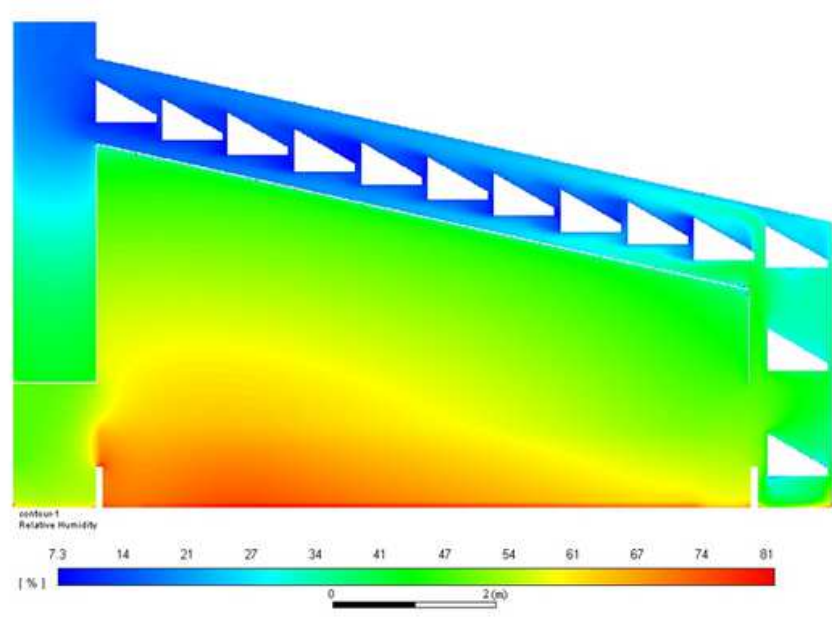

(b) Relative humidity contours

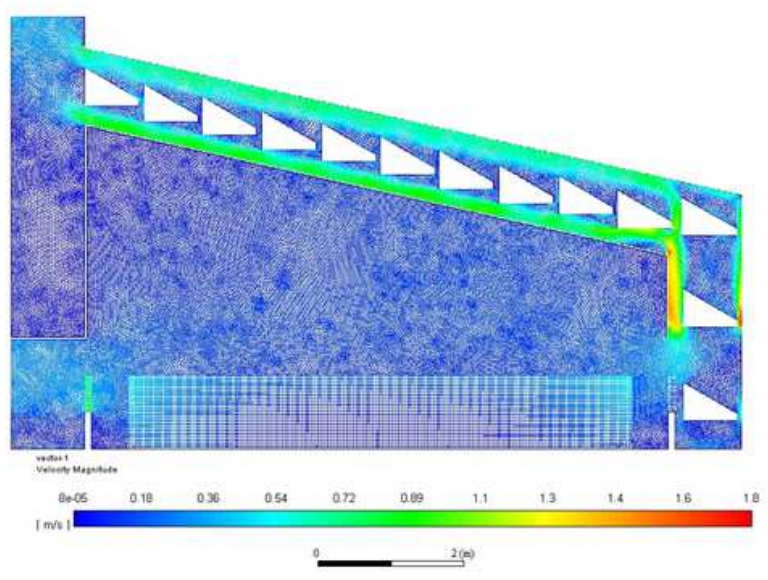

(d) Air velocity vectors

Figure 10

CFD simulation results for air temperature, relative humidity, vapor mass fraction and velocity vector contours inside the $\mathrm{GH}$ at midday of the 21 st of June in Borg AL-Arab Egypt. 


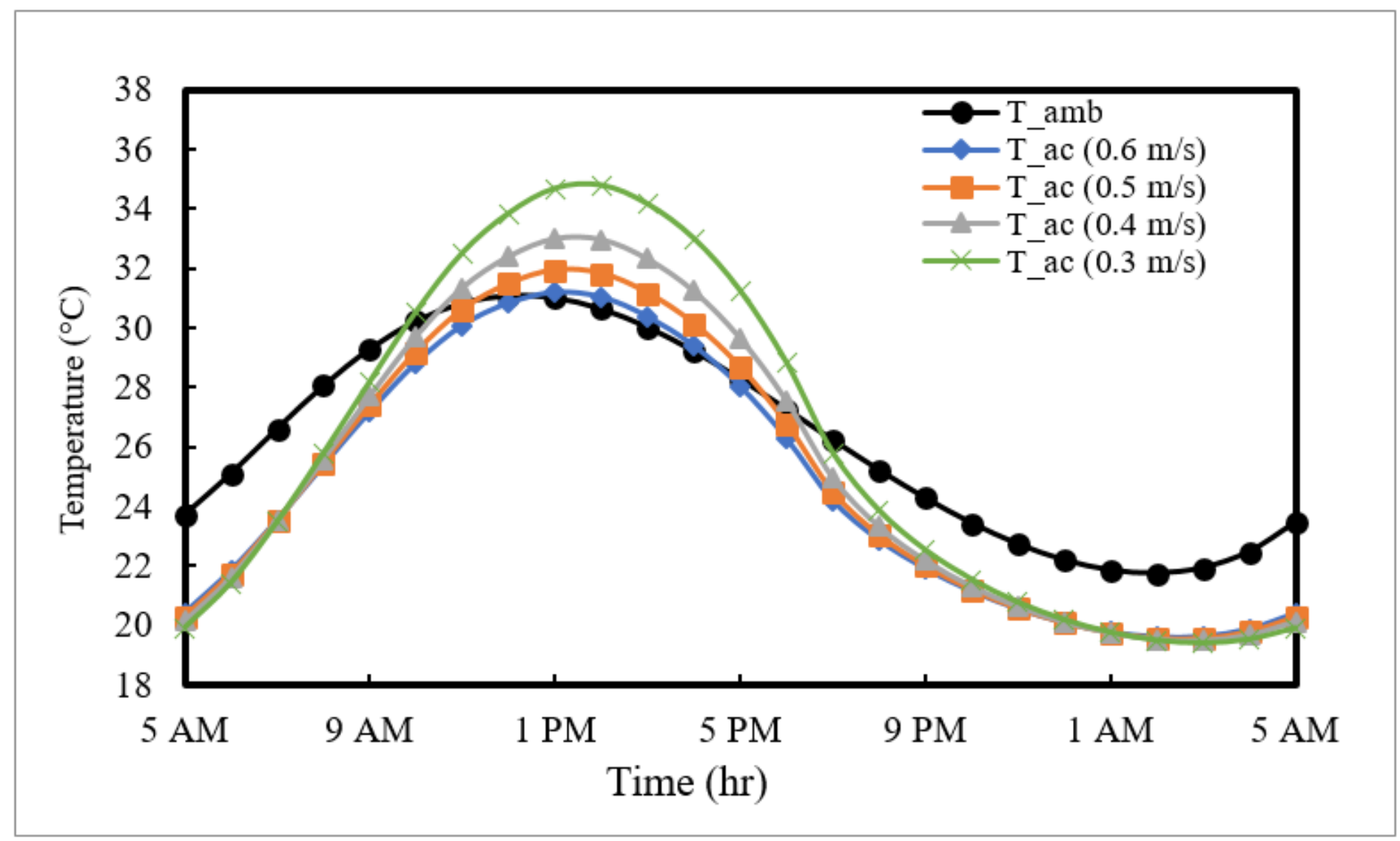

Figure 11

Air Temperature at inclined riser for different air flow velocity for a typical day of 21 st June in Borg ALArab Egypt. 


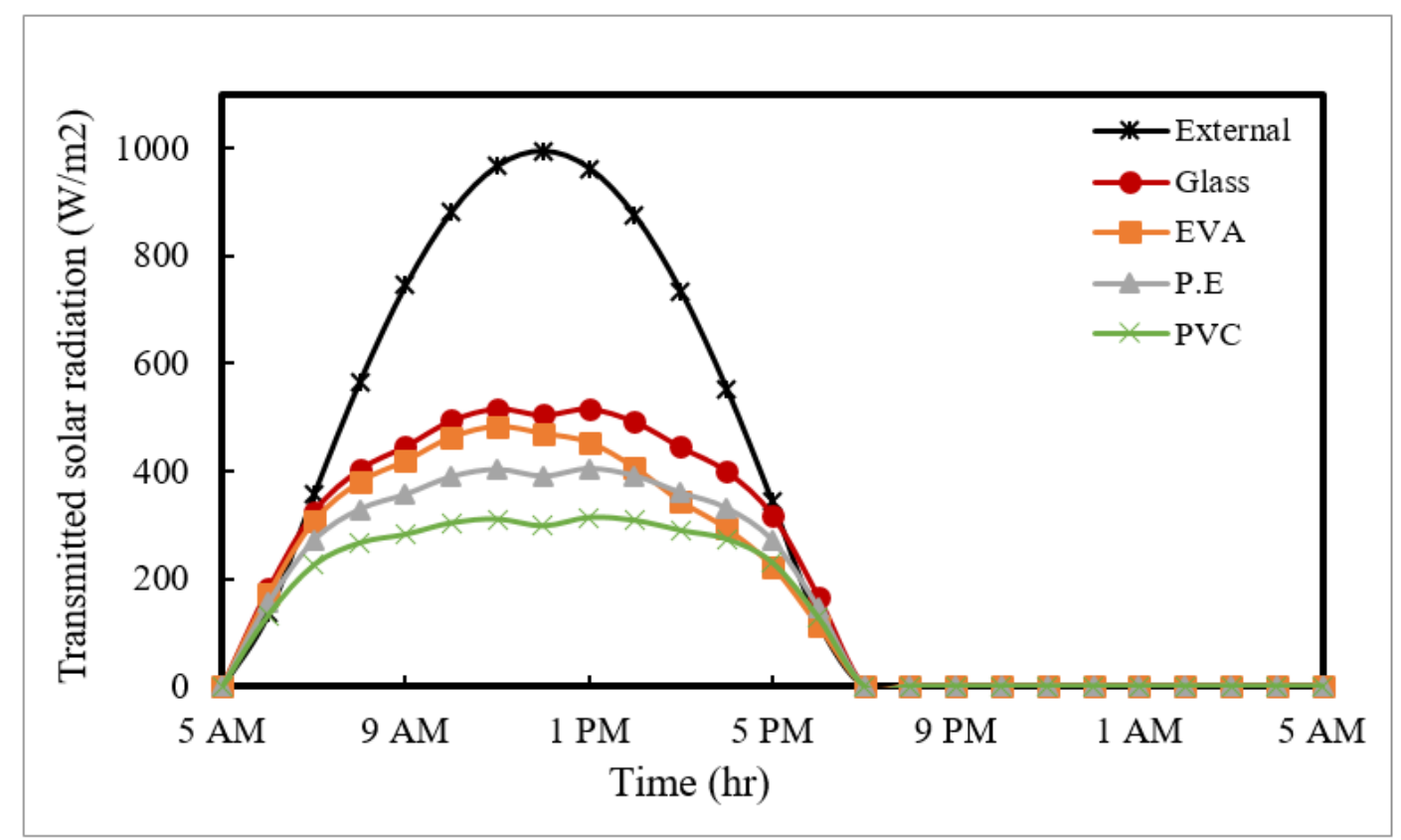

(a) Instantaneously total solar radiation transmitted into GH cavity for different covering materials

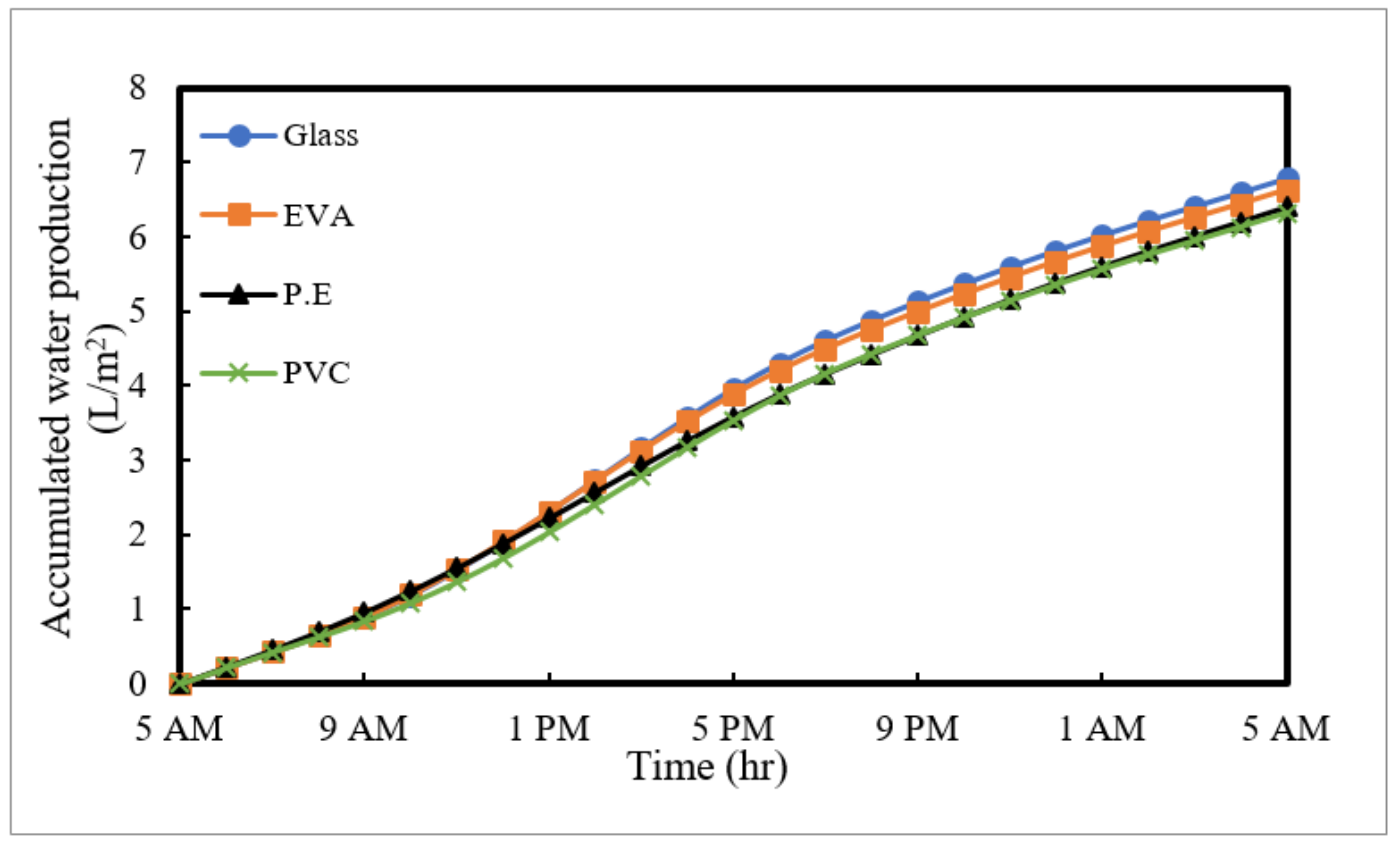

(b) Accumulated water production for different covering materials

Figure 12

Transmitted solar radiation and water production for different covering materials on the 21 st of June in Borg Al-Arab Egypt.

\section{Supplementary Files}


This is a list of supplementary files associated with this preprint. Click to download.

- Supplementary.docx 